\title{
Hyperlipidemic Diet Causes Loss of Olfactory Sensory Neurons, Reduces Olfactory Discrimination, and Disrupts Odor-Reversal Learning
}

\author{
Nicolas Thiebaud, ${ }^{1}$ Melissa C. Johnson, ${ }^{2}$ Jessica L. Butler, ${ }^{1}$ Genevieve A. Bell, ${ }^{1}$ Kassandra L. Ferguson, ${ }^{1}$ \\ Andrew R. Fadool, ${ }^{1}$ James C. Fadool, ${ }^{3}$ Alana M. Gale, ${ }^{4}$ David S. Gale, ${ }^{4}$ and Debra A. Fadool ${ }^{1,5}$ \\ ${ }^{1}$ Department of Biological Science and Program in Neuroscience, Florida State University, Tallahassee, Florida 32306, ${ }^{2}$ Department of Biology, University of \\ West Georgia, Carrollton, Georgia 30118, ${ }^{3}$ Department of Mechanical Engineering, Florida State University, Tallahassee, Florida 32310, ${ }^{4}$ Larry A. Ryle High \\ School, Union, Kentucky 41091, and 5Institute of Molecular Biophysics, Florida State University, Tallahassee, Florida 32306
}

Currently, 65\% of Americans are overweight, which leads to well-supported cardiovascular and cognitive declines. Little, however, is known concerning obesity's impact on sensory systems. Because olfaction is linked with ingestive behavior to guide food choice, its potential dysfunction during obesity could evoke a positive feedback loop to perpetuate poor ingestive behaviors. To determine the effect of chronic energy imbalance and reveal any structural or functional changes associated with obesity, we induced long-term, diet-induced obesity by challenging mice to high-fat diets: (1) in an obesity-prone (C57BL/6J) and obesity-resistant $\left(K v 1.3^{-/-}\right)$line of mice, and compared this with (2) late-onset, genetic-induced obesity in $M C 4 R^{-/-}$mice in which diabetes secondarily precipitates after disruption of the hypothalamic axis. We report marked loss of olfactory sensory neurons and their axonal projections after exposure to a fatty diet, with a concomitant reduction in electro-olfactogram amplitude. Loss of olfactory neurons and associated circuitry is linked to changes in neuronal proliferation and normal apoptotic cycles. Using a computer-controlled, liquid-based olfactometer, mice maintained on fatty diets learn reward-reinforced behaviors more slowly, have deficits in reversal learning demonstrating behavioral inflexibility, and exhibit reduced olfactory discrimination. When obese mice are removed from their high-fat diet to regain normal body weight and fasting glucose, olfactory dysfunctions are retained. We conclude that chronic energy imbalance therefore presents long-lasting structural and functional changes in the operation of the sensory system designed to encode external and internal chemical information and leads to altered olfactory- and reward-driven behaviors.

Key words: chemical senses; circuitry; metabolism; obesity; olfactory; sensory

\section{Introduction}

Obesity leads to well-supported cardiovascular, inflammatory, and cognitive declines (Hedley et al., 2004). Although consumption of diets high in fat are found to cause nervous system dysfunction, whether such diets structurally and functionally impact

Received Aug. 7, 2013; revised March 13, 2014; accepted April 14, 2014.

Author contributions: N.T. and D.A.F. designed research; N.T., M.C.J., J.L.B., G.A.B., K.L.F., A.R.F., J.C.F., A.M.G., D.S.G., and D.A.F. performed research; J.C.F. contributed unpublished reagents/analytic tools; N.T., M.C.J., J.L.B., G.A.B., K.LF., A.R.F., A.M.G., D.G., and D.A.F. analyzed data; N.T. and D.A.F. wrote the paper.

This work was supported by National Institutes of Health Grants R01DC003387, R01DC13080, and ARRAR01003387-SUMM (Summer Experience for High School Students) from the National Institutes of Deafness and Communication Disorders, a Research and Creativity Planning Grant from the Florida State University (FSU), an equipment grant from the FSU Program in Neuroscience, a Neuroscience Fellowship, and Bess-Ward Scholarship from the FSU Honors College. We thank Christopher Kovach, Stephanie Zych, and Wesley Joshua Earl for routine animal husbandry and genotyping; Bayer Healthcare for the donation of Ascensia glucose strips for our research; and the undergraduate scholars who helped in histological processing, neuronal counting, or in the guided operation of the olfactometer: Nicole Benjamin, Chris Calixte, Carlos Cano, Arda Celen, Sheena Donnellan, Elizabeth Lopez, Mauricio Parra-Ferro, Carlie Hoffman, Courtney Hylton, Heidi Lilley, Jordan Johnson, Kim Loberbaum, Adarsha Malla, Michael Porter, Jad Mourad, Sandy Woods, Margaret Yip, and Rasheedat Zakare.

The authors declare no competing financial interests.

Correspondence should be addressed to Dr. Debra A. Fadool, Florida State University, Program in Neuroscience and Molecular Biophysics, 319 Stadium Drive, Suite 3008 KIN, Tallahassee, FL 32306. E-mail: dfadool@bio.fsu.edu. DOI:10.1523/JNEUROSCI.3366-13.2014

Copyright $\odot 2014$ the authors $\quad 0270-6474 / 14 / 346970-15 \$ 15.00 / 0$ our sensory systems is largely unexplored. Metabolic disorders perturb neuronal plasticity and general CNS function, particularly as targeted dysfunctions of the hypothalamus or hippocampus (Park et al., 2010; Pierce and Xu, 2010; McNay et al., 2012; Yi et al., 2012). Proinflammatory responses and microglia release of cytokines are suspected to incite long-term metabolic disorders brought on by diet-induced obesity (DIO), which may in turn disturb both leptin and insulin sensitivity of the individual (Zhang et al., 2008; Kleinridders et al., 2009).

Recently, it has been recognized that the olfactory system acts not only as a detector of external chemical information but also as a detector of the internal chemistry of metabolism (PalouzierPaulignan et al., 2012). The detection and hedonic representation of food odors can be influenced by satiety, thereby influencing the initiation or termination of eating behaviors (Yeomans, 2006; Aime et al., 2007; Prud'homme et al., 2009). During the past decade, a myriad of metabolic cues, whose circulating levels are dependent on nutritional status (i.e., leptin, insulin, glucose), have been identified to act as direct modulators of the peripheral and central neuronal pathways involved in olfactory functions (for review, see Palouzier-Paulignan et al., 2012). Because the olfactory system drives behavioral decisions about food choice 

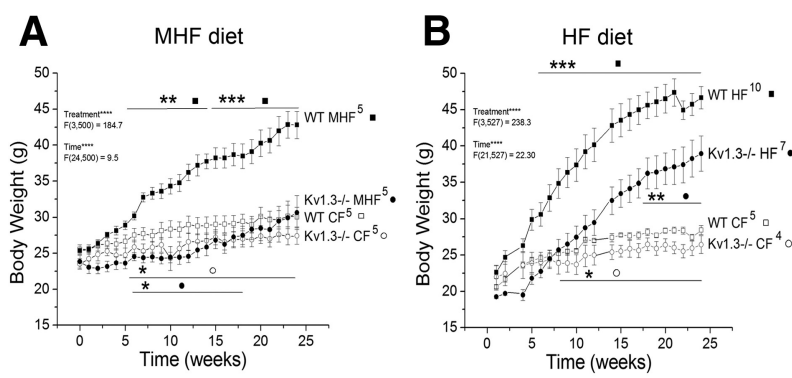

C

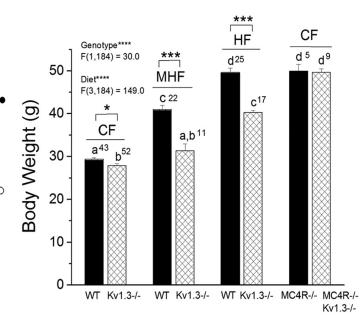

D

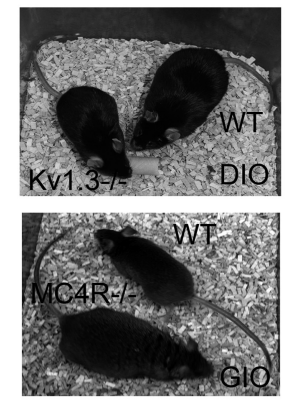

E

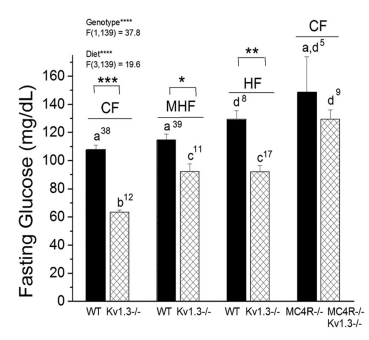

$\mathbf{F}$

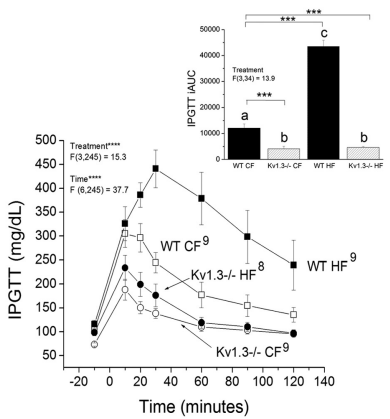

Figure 1. Resistance to increased body weight, elevated fasting glucose, and associated glucose clearance for male mice on Kv1.3-null backgrounds (Kv1.3 ${ }^{-I-}$ ) challenged on various diets and expressing the M72-IRES-tau-LacZ transgene (see Materials and Methods). $\boldsymbol{A}, \boldsymbol{B}$, Line graph of the mean \pm SEM body weight for mice weaned to CF ( $13.5 \% \mathrm{fat}), \operatorname{MHF}(32 \% \mathrm{fat})$, or HF ( $60 \% \mathrm{fat}$ ) diets. $C$, Bar graph of the mean body weight taken at the 6 month time point. Data are grouped to compare genotype within similar $\operatorname{diet}\left(\mathrm{CF}, \mathrm{MHF}\right.$, or $\mathrm{HF}$ ) and are also compared with $M C 4 R^{-1-}$ and $M C 4 R^{-1-} \mathrm{Kv} 1.3^{-1-}$ mice on CF chow similarly measured 6 months after weaning. Black bars represent WT. Hatched bars represent $K v 1.3^{-1-}$ or $K v 1.3^{-1-}$ background. D, (Top) Photograph of a representative WT and Kv1.3 ${ }^{-1-}$ mouse 24 weeks after weaning to MHF diet that promotes DI0. Bottom, Photograph of a representative WT and $M C 4 R^{-1-}$ mouse 24 weeks after weaning to a CF diet in which late-onset, genetic-induced obesity $(G \mid 0)$ is developed because of disruption of the hypothalamic axis. $\boldsymbol{E}$, Bar graph of the fasting glucose taken by tail bleed for a subsample of the mice in $\boldsymbol{C}$. $\boldsymbol{F}$, Line graph of the mean \pm SEM plasma glucose concentration over time in the IPGTT. Inset, Bar graph of the mean \pm SEM integration of the area under the curve (iAUC). $\boldsymbol{A}-\boldsymbol{C}, \boldsymbol{E}, \boldsymbol{F}$, Number of mice per treatment group as indicated. Analyzed factors, degrees of freedom, number of measurements, Fvalue, and level of significance ${ }^{* * * *} p \leq 0.0001,{ }^{* * *} p \leq 0.001$, $\left.{ }^{* *} p \leq 0.01,{ }^{*} p \leq 0.05\right)$. NS, Not significant $(p>0.05)$ as indicated in the panels. Two-way ANOVA was a blocked factorial design $(\boldsymbol{A}, \boldsymbol{B}, \boldsymbol{F})$ or completely randomized $(\boldsymbol{C}, \boldsymbol{E})$. One-way ANOVA ( $\boldsymbol{F}$, inset). Post hoc tests were performed (in this and subsequent analyses) with a Bonferroni correction for mean-wise comparisons and were indicated with lettering; means noted with the same letter are not significantly different. Highlighted comparisons to the WT mean are also indicated with a bar and varying $p$ values in the post hoc analyses.

and consumption, it is well poised to be modulated by obesity when there is an imbalance in the utilization of glucose and insulin, among other energy important molecules, which are detected by the olfactory bulb (OB) (Fadool et al., 2000, 2011; Lacroix et al., 2008; Tucker et al., 2013).

Gene-targeted deletion of the Kv1.3 channel $\left(K v 1.3^{-/-}\right)$generates mice with a "Super-smeller" phenotype with mitral cell biophysical properties that mimic those after insulin-stimulation in wild-type (WT) animals (Fadool et al., 2004, 2011). Quite curiously, these mice have a prominent metabolic phenotype: (1) they have a thin body morph attributed to an elevation in basal metabolism; (2) they are resistant to obesity when challenged with a moderately high fat diet of $32 \%$ fat or when crossed to a genetic model of obesity in which the melanocortin receptor 4 pathway is deleted $\left(M C 4 R^{-1-}\right)$; (3) they exhibit increased sensitivity to insulin that is attributed to increased glucose 4 transporter translocation to the membrane; and (4) their resistance to DIO can be eliminated through the removal of the OB (Xu et al., 2003, 2004; Fadool et al., 2004; Tucker et al., 2008, 2012b).

To reveal the impact of energy imbalance in a sensory system that is linked with ingestive behavior, we induced long-term DIO by challenging mice to high-fat diets (1) in an obesity-prone
(C57BL/6J) and obesity-resistant $\left(K v 1.3^{-/-}\right)$ line of mice, and compared this with (2) late-onset, genetic-induced obesity in $M C 4 R^{-1-}$ mice in which diabetes secondarily precipitates after disruption of the hypothalamic axis (Huszar et al., 1997; Berthoud et al., 2006). We find that overconsumption of fat causes structural and functional changes in the operation of the olfactory system, which in turn could evoke poor food choice decisions linked to the dysfunction in olfactorydriven behavior.

\section{Materials and Methods}

Animal care and transgenic lines. All mice were housed at the Florida State University (FSU) vivarium in accordance with institutional requirements for animal care. Mice were singly housed in conventional style open cages using a 12/12 h light/dark cycle. Upon weaning (postnatal day (P) 23), male mice were fed ab libitum on either a control diet (CF) of Purina 5001 Rodent Chow $(28.05 \%$ kcal protein, $59.81 \%$ kcal carbohydrate, and $13.5 \%$ kcal fat), a moderately high-fat condensed milk diet (MHF), catalog number D12266B, from Research Diets (16.8\% kcal protein, $51.4 \%$ kcal carbohydrate, and $31.8 \%$ kcal fat) or high-fat diet (HF), catalog number D12492 (HF; 20\% kcal protein, $20 \% \mathrm{kcal}$ carbohydrate, and $60 \% \mathrm{kcal}$ fat) for a duration of 24 weeks during which body weight was monitored weekly. Behavioral experiments, tissue harvest, electro-olfactogram, and serum chemistry experiments were performed $2 \mathrm{~h}$ into the dark cycle to standardize any circadian effects.

To visualize and quantify neuroanatomical changes in the olfactory system in response to obesity, three lines of mice with different body weights and degrees of susceptibility to adiposity were selected, namely, DIO-prone C57BL/ 6J-derived mice (West et al., 1992; Williams et al., 2003; Collins et al., 2004); obesity-resistant Kv1.3 ${ }^{-1-}$ mice (Xu et al., 2003; Fadool et al., 2004; Tucker et al., 2012b); and late-onset, genetically obese, melanocortin 4 receptor-null mice $\left(M C 4 R^{-1-}\right)$ (Butler and Cone, 2002; Balthasar et al., 2005; Balthasar, 2006). Several transgenic mouse lines in C57BL/6J backgrounds were generously made available to our use by Dr. Peter Mombaerts (Max Plank Institute, Frankfort, Germany), whereby these lines allowed labeling of either mature olfactory sensory neurons (OSNs) using an olfactory marker protein GFP transgene (OMP-GFP) (Potter et al., 2001) or the identification of specific classes of odor receptor-expressing olfactory sensory neurons (OSNs) and their axonal projections (i.e., M72-IREStau-LacZ; gene oflr160) (Mombaerts et al., 1996; Zheng et al., 2000). Kv1.3-null mice $\left(K v 1.3^{-1-}\right)$ were generated previously by deleting a large promoter region and the N-terminal third of the Kv1.3 coding sequence (Xu et al., 2003, 2004) and were generously provided by Drs. Leonard Kaczmarek and Richard Flavell (Yale University, New Haven, $\mathrm{CT})$. The loxTB MC4R mice $\left(M C 4 R^{-1-}\right)$ were generated by insertion of a loxP-flanked transcriptional blocking sequence between the MC4R transcription start sequence and $112 \mathrm{bp}$ upstream of ATG to produce a complete block of MC4R transcription and protein production in a C57B6/J and Sv129 mixed background (Balthasar et al., 2005) and were generously provided by Dr. Joel Elmquist (University of Texas Southwestern Medical Center, Dallas, TX). M72-IRES-tau-LacZ/Kv1.3 $3^{-1-}$ double transgenics were previously generated and compared with their 
$\mathrm{Kv} 1.3^{+/+}$counterparts as described and anatomically characterized by Biju et al. (2008). These lines could then be placed on modified diets to ascertain anatomical changes when challenged with an MHF or HF diet that would precipitate DIO. To retain a genetic marker for the M72expressing OSNs, we then bred the MC4R ${ }^{-1-}$ mice to the M72-IREStau-LacZ/Kv1.3 $3^{+/+}$and M72-IRES-tau-LacZ/Kv1.3. $3^{-1-}$ lines to achieve triple transgenic lines that would be useful in exploring genetic models of late-onset, genetic-linked obesity rather than DIO. Because a majority of the mice in this study have a M72-IRES-tau-LacZ background as the genetic marker, for ease of reading we have dropped its reference. Therefore, in the DIO experiments, for simplicity, the M72-IRES-tau$\mathrm{LacZ} / \mathrm{Kv} 1.3^{+/+}$will be referred to as WT, whereas the $\mathrm{Kv} 1.3^{-/-}$mice in this report are the double transgenics, or M72-IRES-tau-LacZ/Kv1.3 $3^{-1-}$. In the genetic-induced obesity experiments, also for simplicity, the M72-IRES-tau-LacZ/Kv1.3 ${ }^{+/+} / M C 4 R^{+/+}$mice are the WT mice, the M72-IRES-tau-LacZ/Kv1.3 ${ }^{+/+} / M_{C} 4 R^{-1-}$ mice will be referred to as $M C 4 R^{-1-}$, and the M72-IRES-tau-LacZ/Kv1.3 $3^{-1-} / M C 4 R^{-1-}$ will be referred to simply as $M C 4 R^{-1-} / K v 1.3^{-1-}$.

Serum chemistry and adiposity measurements. After transition to modified diets, all experimental mice were monitored biweekly for any signs of poor health (i.e., dermatitis). Only male mice were used in our experiments. Body weights were measured weekly with a final adult body weight measurement taken 6 months after the start of the modified diet. Any mice that failed to progressively thrive were removed from our analysis as an indicator of poor health. A subset of the mice used in both anatomical and biochemical experiments were used to determine plasma glucose and postmortem analysis of adiposity. Tail blood sampling from $12 \mathrm{~h}$ fasted animals was used to determine fasting glucose levels using an Ascensia Contour Blood Glucose Monitoring System (Bayer Healthcare). Intraperitoneal glucose tolerance tests (IPGTT) were similarly performed after fasting by monitoring clearance of serum glucose over time in response to $1 \mu \mathrm{g} / \mathrm{ml}$ glucose per kg body weight (University of Virginia Vivarium Protocols, Susanna R. Keller). Confirmed total fat pad adiposity was determined as a confirmation of increased adiposity by a combined weight of epididymal, visceral, subcutaneous, and retroperitoneal fat pads as previously described (Tucker et al., 2012a).

Solutions, reagents, and antibodies. Solutions used for protein sample or tissue preparation, namely, nonidet-P40 protease and phosphatase inhibitor lysis buffer (NP40 PPI), homogenization buffer (HB), protease and phosphatase inhibitor mixture (PPI), blocking solution, and PBS, were made as described by Tucker and Fadool (2002) or Biju et al. (2008). The three buffers $(\mathrm{A}-\mathrm{C})$ used to visualize $\beta$-galactosidase reaction product contained the following: Buffer A $(0.1 \mathrm{M}$ phosphate buffer, $2 \mathrm{~mm}$ $\mathrm{MgCl}_{2}, 5$ mM EGTA, pH 7.4; Buffer B (0.1 M phosphate buffer, $2 \mathrm{~mm}$ $\mathrm{MgCl}_{2}, 0.01 \%$ sodium deoxycholate, and $0.02 \%$ Nonidet $\mathrm{P} 40, \mathrm{pH} 7.4$ ); Buffer C (Buffer B with $5 \mathrm{~mm}$ potassium ferricyanide, $5 \mathrm{~mm}$ potassium ferrocyanide, and $600 \mu \mathrm{g} / \mathrm{ml} \mathrm{X-gal.} \mathrm{X-gal} \mathrm{was} \mathrm{purchased} \mathrm{from} \mathrm{Research}$ Products International.

Anti- $G_{\alpha o l f}(1: 1000)$ was a generous gift from Dr. Albert Farbman (Northwestern University, Evanston, IL), who generated the antiserum by using the same antigen as Reed's antiserum (CY coupled to KTAEDQGVDEKERREA, near the amino terminus of rat $\mathrm{G}_{\text {olf }}$ (Jones and Reed, 1989). The specificity of anti- $\mathrm{G}_{\alpha o l f}$ has been previously confirmed at both the light microscope and ultrastructural level using preadsorption and omission of primary antiserum, where it has been found to predominantly label olfactory cilia of mature OSNs (Mania-Farnell and Farbman, 1990; Menco et al., 1994). Polyclonal antisera effective in detergent-solubilized membrane fractions and histological sections for recognizing mMOR28 (Barnea et al., 2004) were a generous gift from Dr. Richard Axel (Columbia University, New York). $\alpha$-mMOR28 antisera were generated against two unique epitopes: one in the extracellular domain (residues 167-182) and another in the C-terminal tail domain (residues 302-313). These antisera were previously fully characterized by the Axel laboratory (Barnea et al., 2004; online supplemental data). Specificity controls for $\alpha$-mMOR28 included complete overlapping patterns with those generated by $\beta$-galactosidase staining using MOR28-IREStau-LacZ mice. Lack of antibody staining was also confirmed in isolated membrane fractions of adult main olfactory epithelium (MOE) in mice with a gene-targeted deletion of MOR28. Immunoprecipitated MOR28
A

A
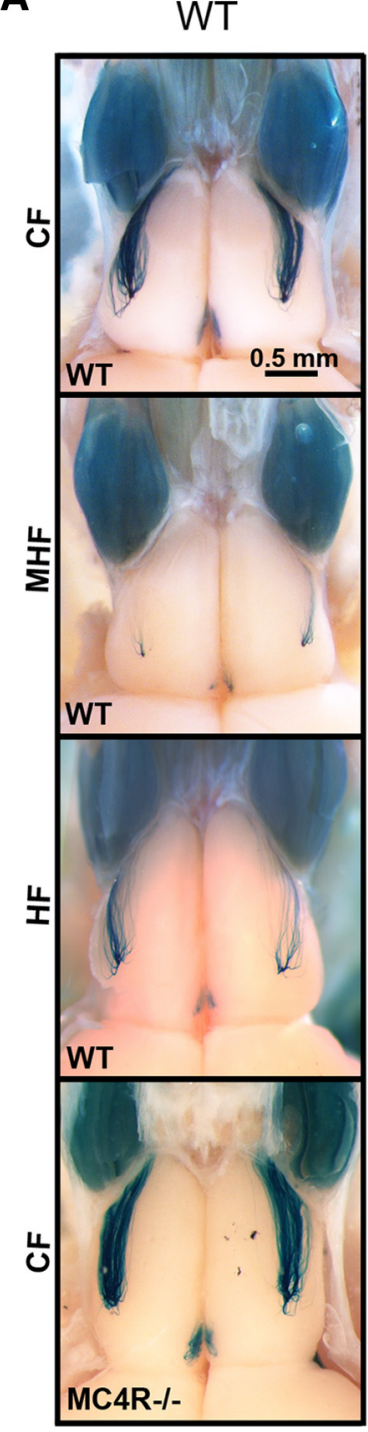

B

Kv1.3-/-
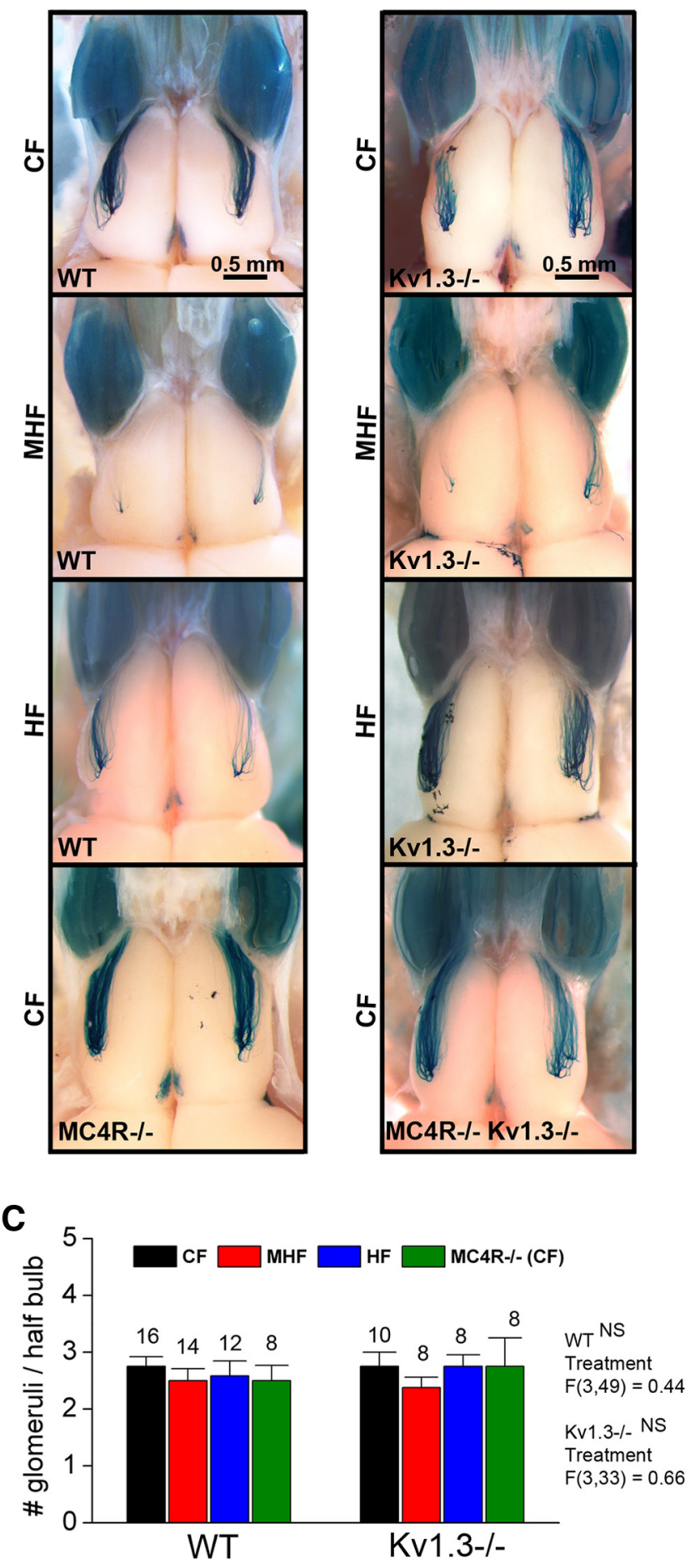

Figure 2. Axonal projections to the M72 glomerulus are reduced following an MHF diet in both WT and Kv1.3 $3^{-1-}$ mice, whereas the response to the HF diet is differential across genotypes. The number of glomerular targets is not modified with diet regardless of genotype. $\boldsymbol{A}$, Whole-mount images of the OBs from WT littermates maintained on a CF, MHF, or HF diet for 6 months. $\boldsymbol{B}$, Same as in $\boldsymbol{A}$, but for $K v 1.3^{-/-}$littermates. $\boldsymbol{A}, \boldsymbol{B}$, Bottom panels, Representative genetically obese mice on the WT $\left(M C 4 R^{-1-}\right)$ or $K v 1.3^{-1-}$ background $\left(M C 4 R^{-1-} / K v 1.3^{-I-}\right)$, respectively. C, Mean \pm SEM number of $M 72$ glomeruli/half OB following fat feeding or induction of the $M C 4 R^{-1-}$ phenotype for the same 6 month duration. Not significantly different (NS) by one-way ANOVA performed within genotype ( $p \geq 0.05$ ). Noted sample sizes represent number of half $0 \mathrm{Bs} /$ treatment. 
A

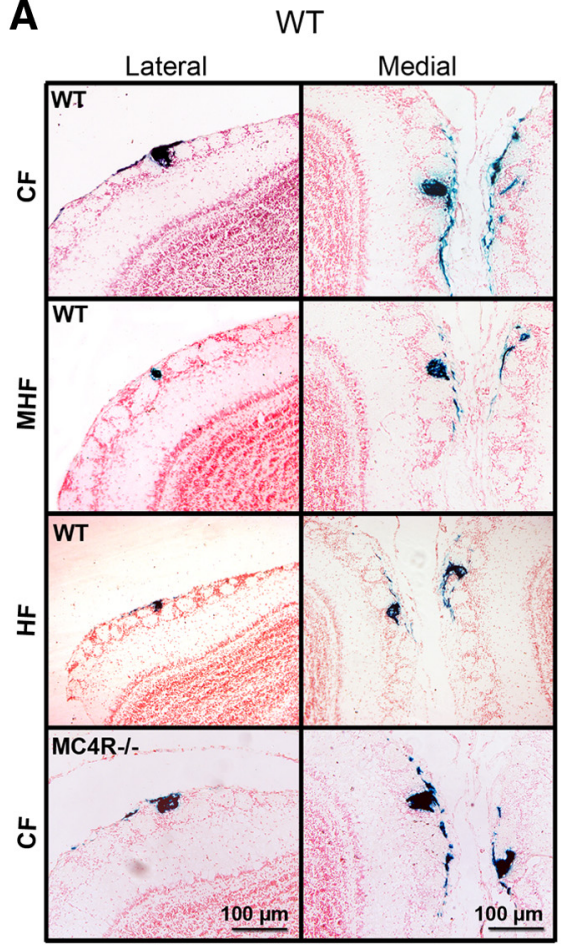

C

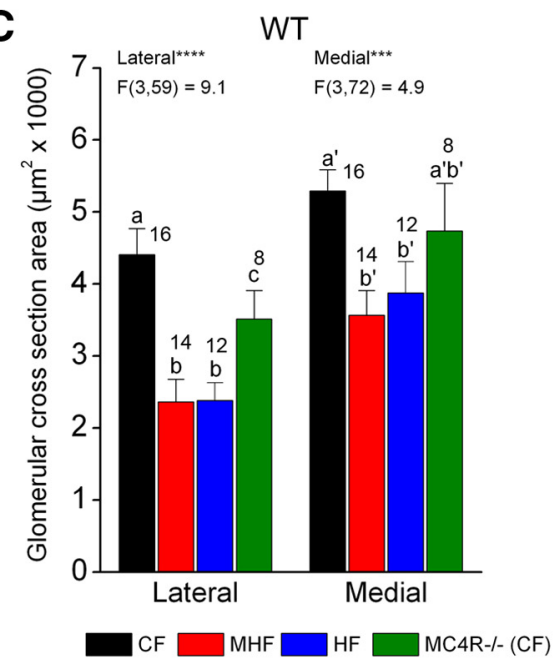

B

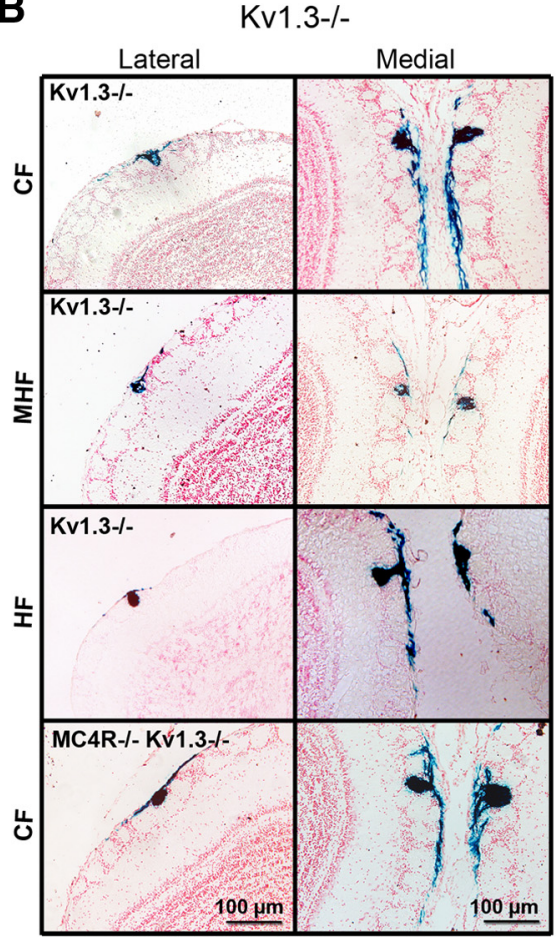

D

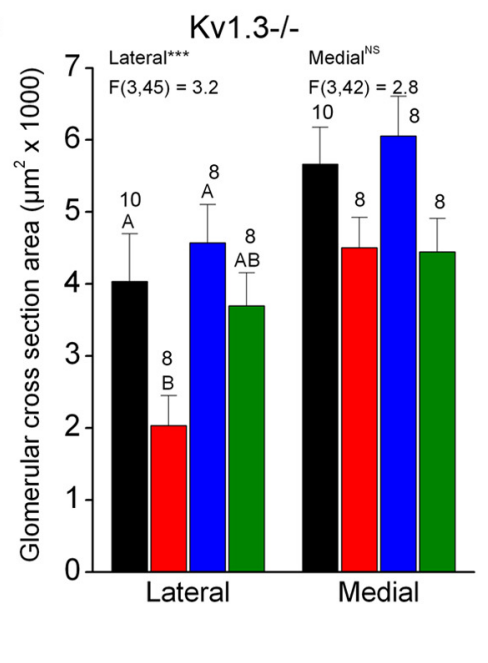

Figure 3. The size of axonal projections to the M72 glomerulus is reduced after an MHF or HF diet. $\boldsymbol{A}, \boldsymbol{B}$, Same experimental paradigm as in Figure 2, but showing the (left) lateral versus (right) medial M72 glomerulus. C, D, Glomerular cross-sectional area for mice in $(\boldsymbol{A}, \boldsymbol{B})$ quantifying $(\boldsymbol{C})$ WT versus $(\boldsymbol{D}) \mathrm{Kv} 1.3^{-1-}$ backgrounds. One-way ANOVA performed within genotype for each type of glomerulus. ${ }^{* *} p \leq 0.001$. ${ }^{* * *} p \leq 0.0001$. NS, Not significant $(p>0.05)$. Noted sample sizes represent number of half $\mathrm{OBs} /$ treatment. Error bars are mean $\pm \mathrm{SEM}$.

from wild-type mice also demonstrated predicted band shift after expected glycoprotein enzymatic cleavage. Further analysis was completed using MBP-based MOR28 fusion proteins to demonstrate both expected size/mobility and band specificity (Barnea et al., 2004). Ki67 is a marker for cell proliferation (Gerdes et al., 1984); rabbit-polyclonal antisera antiKi67 (1:300) was a generous gift from Dr. Stanley Watson (University of Michigan) (Perez et al., 2009). Rabbit activated caspase-3 antibody (1: 100) was purchased from Promega and was directed against a peptide from the p18 fragment of human caspase-3. The polyclonal antisera were affinity purified using a peptide corresponding to the cleaved region of caspase-3. Anti-Iba-1 (1:500) was directed against amino acids 135-147 of the human Iba and was used to recognize microglia (Abcam, ab5076). Finally, anti-rabbit IgG Cy3 secondary antisera (Jackson ImmunoResearch Laboratories) were used in immunohistochemistry experiments
(1:200) and HRP-conjugated, species-specific secondary antisera (Sigma Chemical; GE Healthcare Bio-Sciences) were used for Western analysis (typically 1:3500).

$X$-gal staining and quantitative analysis. Tissue sections and whole mounts were histologically processed as previously described (Biju et al., 2008). Briefly, mice were killed with an overdose of sodium pentobarbital as per FSU Resources and American Veterinary Medical Association (AVMA)-approved methods and then immediately received an intracardiac perfusion of PBS followed by 4\% PFA for $5 \mathrm{~min}$. Heads were postfixed in $4 \%$ PFA/PBS overnight at $4^{\circ} \mathrm{C}$, rinsed in PBS, and then decalcified in $0.3 \mathrm{~m}$ EDTA for $96 \mathrm{~h}$ at $4^{\circ} \mathrm{C}$. Both nasal epithelia and OBs were exposed and rinsed in PBS. A total of 130 animals across the four genotypes (WT, $K v 1.3^{-1-}, M_{C} 4 R^{-1-}, M_{C} 4 R^{-1-}$, $K v 1.3^{-/-}$) and three dietary regimens (CF, MHF, HF) were processed at 6 months of age for either whole-mount staining or cryosectioning. Specimens to be sectioned were cryoprotected in $10 \%$ then $30 \%$ sucrose PBS at $4^{\circ} \mathrm{C}$ before being frozen in OCT compound-embedding medium (Miles Diagnostic Division) and stored at $-80^{\circ} \mathrm{C}$ until day of cryosectioning. Cryosectioning was performed on a LEICA model CM1850 cryostat (Leica Microsystems) to yield coronal sections at $16 \mu \mathrm{m}$ thickness that were transferred to $1 \%$ gelatin-coated Superfrost slides (VWR International) and stored at $-20^{\circ} \mathrm{C}$ until X-gal stained. For visualizing $\beta$ galactosidase, both whole mounts and slides were washed with Buffer A for $5 \mathrm{~min}$ and then again for $25 \mathrm{~min}$ at room temperature. Tissues were then incubated twice with Buffer B for 5 min each, followed by a $6 \mathrm{~h}$ incubation in Buffer $\mathrm{C}$ at room temperature.

Whole mounts were examined with a Leica MZ FLIII stereomicroscope. The number of M72 glomeruli per OB were counted within genotype and compared across dietary treatment. Cryosections were counterstained with neutral red after the X-gal processing to visualize targets of projections or number of M72expressing OSNs by light photomicroscopy (Axiovert S 100, Zeiss). Digital images were captured by using a Zeiss Axiocam digital camera and AxioVision software and then processed with Adobe Photoshop. At least four MOEs that were sectioned coronally in entirety were used to quantify M72-expressing OSN abundance. Manual counts of positively identified odor receptor (OR)-expressing OSNs were compared within genotype and across diet. By using the ImageJ software (National Institutes of Health Windows version; http://rsbweb.nih.gov/ij/index.html), the cross-sectional area of the M72 glomerulus in these sections was also measured and subjected to an identical analysis for each respective glomerulus and particular location within the bulb (lateral vs medial). Because the factor of genotype upon circuitry and OSN abundance had been previously determined for Kv1.3 ${ }^{-1-}$ mice (Biju et al., 2008), our analyses were narrowed to within genotype to determine the impact of diet alone.

Immunofluorescence. A total of 14 OMP-GFP or $\mathrm{Kv}_{1.3} 3^{-1-}$ mice were similarly challenged upon weaning (P23) with modified diets (CF, MHF, or HF) for 6 months and then were killed, fixed perfused, and prepared for cryosectioning as described above. Immunochemical characteriza- 
tion of active caspase-3, TUNEL, Ki67, and Iba-1 were performed in the MOE of these mice. The only modification was that section thickness was reduced to $10 \mu \mathrm{m}$ to better visualize the fluorescent signal. Prepared frozen sections were air-dried for $30 \mathrm{~min}$, fixed in 1\% PFA/PBS, washed 3 times in PBS, and then incubated for $30 \mathrm{~min}$ in PBS. After the blocking step, sections were rinsed with $0.1 \%$ Tween $20 /$ PBS before overnight antiserum incubation (dilution in PBS) while protecting from light and maintaining slides at $4^{\circ} \mathrm{C}$. The immunofluorescence signal was detected after $2 \mathrm{~h}$ incubation with host-specific $\mathrm{Cy} 3$ secondary antisera diluted in PBS (1:400; Jackson ImmunoResearch Laboratories). After three washes in PBS, nuclei were additionally stained by incubating slides for $5 \mathrm{~min}$ in DAPI (Fisher Scientific) in PBS $(1: 15,000)$, washing again in PBS, and coverslipping with Fluoromount G (Southern Biotechnology) to prevent photobleaching.

Apoptotic cells in the MOE were detected using rabbit activated caspase- 3 antibody or by TUNEL following the manufacturer's recommendations (ApopTag Red in situ apoptosis detection kit; Millipore). The TUNEL assay detects in situ fragmentation of nuclear DNA that occurs during apoptosis (Gavrieli et al., 1992). Proliferative activity was determined after immunodetection of Ki67 protein in the basal progenitor cells. Immunoreactive cells were manually counted by a single investigator taking samples from the septum, the ectoturbinate 2 , and the endoturbinate IIb according to the Ressler nomenclature (Ressler et al., 1993). For each animal, 10-12 sequential sections were quantified, and the obtained means were compared across 3 or 4 animals per diet treatment group. Data are expressed as number of immunoreactive cells per centimeter and reported as the mean \pm SEM. Differences in neuronal abundance between the diet treatment groups were identified and analyzed within location and genotype.

Biochemistry. After 6 month induction of genetic or dietary obesity, adult mice were decapitated after isoflurane anesthesia as per FSU Laboratory Animal Resources and AVMAapproved methods, and the MOE and OBs were quickly harvested. Tissues were immediately homogenized in HB plus PPI with a Kon-

tes tissue grinder (Kimble Chase; Size 20) on ice. HB-processed tissues were used to isolate membrane proteins as previously described (Tucker and Fadool, 2002). Protein concentrations were determined by a Bradford assay (Bio-Rad), and samples were stored at $-80^{\circ} \mathrm{C}$ until subsequent use. Membrane proteins (15-20 $\mu \mathrm{g} / \mathrm{lane}$ ) were separated on $8-10 \%$ acrylamide gels by SDS-PAGE and electro-transferred to nitrocellulose blots as previously described (Cook and Fadool, 2002; Tucker and Fadool, 2002; Fadool et al., 2004). ECL (GE Healthcare Bio-Sciences) exposure on Fugi Rx film (GE Healthcare Bio-Sciences) was used to visualize labeled proteins. The film autoradiographs were analyzed by quantitative densitometry by using a Hewlett-Packard Scanner (model Scanjet 4850, Hewlett Packard) in conjunction with Quantiscan software (Biosoft). Immunodensity ratios (MHF/CF ratios) were calculated for proteins from SDS gels electrophoresed together, electro-transferred to the same piece of nitrocellulose, and exposed to the same piece of x-ray film to standardize any variance in transfer or ECL exposure. Normalized
B

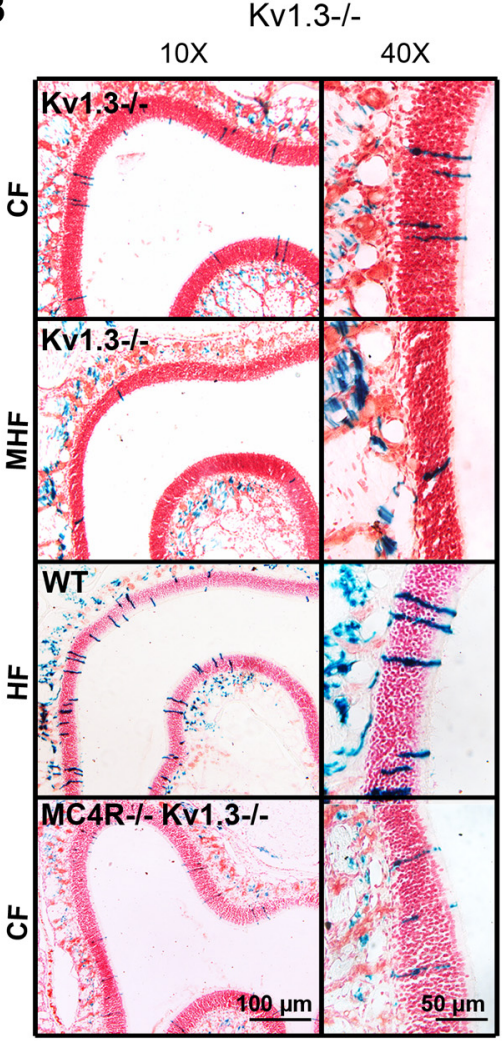

D

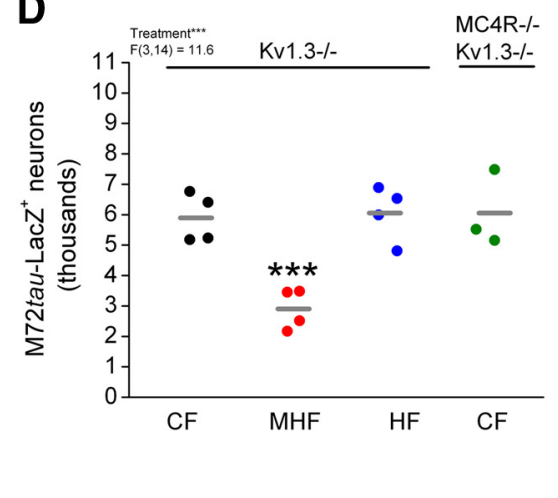

Figure 4. MHF and HF diet cause a loss of OSNs. $A, B$, Same conditions as Figure $2 A, B$ but for the MOE as viewed at low (left, MHF (red), HF (blue), or CF with MHF chow in a tea ball (yellow; CF MHF odor) for 6 months. MC4R $R^{-1-}$ or MC4R ${ }^{-1-} / K v 1.3^{-1-}$ (green). Sample mean (line). One-way ANOVA performed within genotype. ${ }^{*} p \leq 0.05 .{ }^{* *} p \leq 0.01 .{ }^{* * *} p \leq 0.001$.

immunodensity values for a given visualized protein were compared across diet treatment.

Electro-olfactogram (EOG) recordings. After 6 month induction of dietary obesity, 13 adult mice were decapitated after isoflurane anesthesia as per FSU Laboratory Animal Resources and AVMA-approved methods. The head of the killed mouse was cut sagitally, and the septum was carefully removed to expose the medial surface of the olfactory turbinates. The EOG signal was recorded from the dorsal regions of the endoturbinate IIb and III, which contain a high number M72-expressing OSNs. All recordings were made in an isolated experimental room held at saturation humidity using a water-based humidifier (Lowe's Hardware). The surface of the turbinates was continuously exposed to a flow of humidified breathing-quality compressed air $(0.5 \mathrm{~L} / \mathrm{min})$. The stimulus duration (100 ms) was controlled by a picospritzer (Parker Instrumentation) that was used to release the headspace of a $20 \mathrm{ml}$ solution of odorant contained in a $100 \mathrm{ml}$ bottle (Knosys Olfactometry) into the airflow. Odorant stimuli were presented from the lowest to the highest 
A

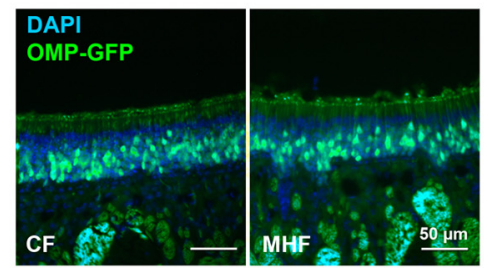

C
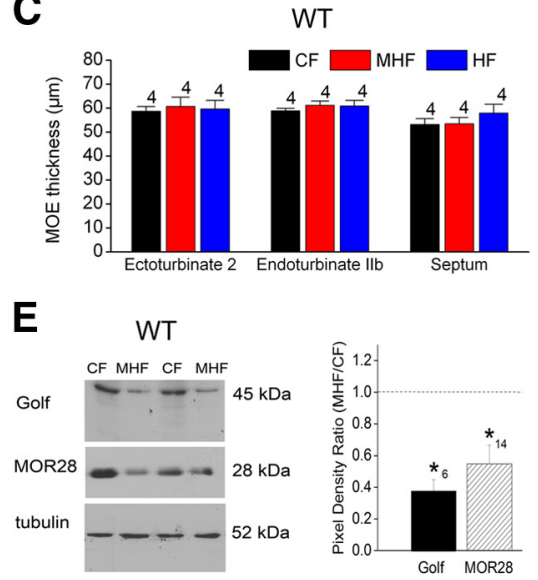

B

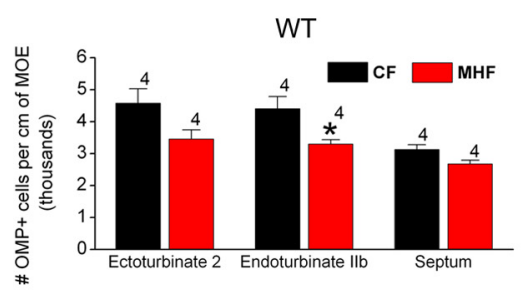

D

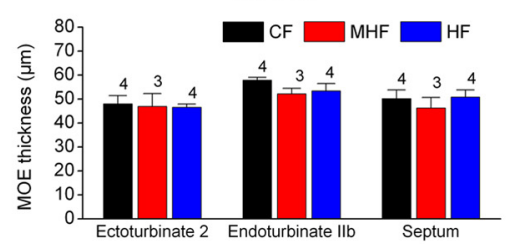

$\mathbf{F}$

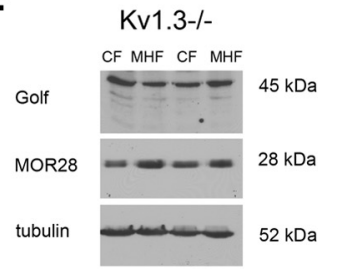

this conditioning paradigm was more suitable for distinguishing sensory ability in mouse models in which diet was the principal experimental variable. Our Knosys was slightly modified after receipt from the manufacturer to provide additional mechanical dampening of the solenoid pinch valves, to incorporate materials for mounting the machine in-line with sterilization of the olfactometer for housing within vivarium barrier facility requirements, and to generate home-written software that facilitated ease of data analysis (FSU Mechanical Engineering Department).

During olfactometry testing, mice were maintained at $85 \%$ of their predeprivation body weight by restricting water to $1-1.5 \mathrm{ml}$ per day. Mice first underwent training using the "Stage 1" program to reinforce licks at the water delivery tube using $2 \mu \mathrm{l}$ water on a random-interval schedule averaging $15 \mathrm{~s}$. All mice completed this stage that consisted of 30 reinforcements. Mice then advanced to the "Stage 3" program whereby trials were initiated by the mouse inserting its snout in the odorsampling port and was followed by a $2.0 \mathrm{~s}$ delivery of the training odor. The odor presentation was binned into ten $0.2 \mathrm{~s}$ periods whereby a criterion response for the mouse to receive water reinforcement was defined as a lick detected in at least six of the $0.2 \mathrm{~s}$ segments. A criterion response was scored as a hit, produced reinforcement, and initiated a $5 \mathrm{~s}$ intertrial interval. Mice were offered a total of 119 trials during a full session of "Stage 3" and were allowed to complete at least four sessions (or 476 individual trials) before advancing to the operant conditioning paradigm, called "D2 training." For "D2 training," discrimination is achieved by assigning the reinforcing odor as

concentration, and a minimum of 1.5 min recovery was allowed between two stimulations to prevent olfactory adaptation. Odorant stock solutions $(1 \mathrm{M})$ were prepared in DMSO and working solutions were prepared extemporaneously by diluting stock solutions with distilled water. The final concentration of DMSO in odorant solutions did not exceed $0.01 \%$. The recording electrode consisted of $\mathrm{Ag} / \mathrm{AgCl}$ wire inside patchclamp borosilicate capillaries (5-8 $\mathrm{m} \Omega$ ) filled with modified Ringer's solution containing the following (in $\mathrm{mM}$ ): $140 \mathrm{NaCl}, 5 \mathrm{KCl}, 2 \mathrm{CaCl}_{2}, 2$ $\mathrm{MgCl}_{2}, 10$ HEPES, adjusted to $\mathrm{pH} 7.2$ and to $320 \mathrm{mOsm} / \mathrm{L}$ with glucose. The recording chamber was made with a Petri dish of $1.5 \%$ agar in Ringer's. The recording and reference electrodes were connected to an Axopatch-200B integrating patch-clamp amplifier (Molecular Devices). The analog signal was low-filtered at $2 \mathrm{kHz}$, digitized with a DigiData 1200 interface (Molecular Devices), and minimally digitally sampled every $100 \mathrm{~ms}$. Analogic control of the picospritzer for stimulus delivery, data capture, and subsequent storage was through pClamp8 with analysis in Clampfit10 software (Molecular Devices). Any response to the presentation of DMSO solvent alone was substracted from the acetophenonestimulated response to control for any mechanical or solvent artifact. All recordings were made in duplicate.

Olfactometry. Mice were trained in a "go no-go" operant conditioning paradigm to recognize an odorant using a computerized, 8 channel liquid dilution olfactometer (Knosys Olfactometer) as previously described (Slotnick and Restrepo, 2005)). This small-animal olfactometer permitted good control of multiple stimuli, stimulus concentration, onset and offset of odorant delivery, and good control of stimulus behavior, as well as provided automation, compared with manual odor behavioral phenotyping that relies upon food finding and related tasks (Fadool et al., 2000, 2004) that have uncontrolled odor delivery from a point source (Slotnick and Restrepo, 2005). Secondarily, because the reward for reinforcement of a recognized positive trained odorant $\left(\mathrm{S}^{+}\right)$was water (and not food),
$\mathrm{S}^{+}$and a second odor or diluent as $\mathrm{S}^{-}$. In this discrimination training, the intertrial interval and the duration of the odor presentation remained the same as in "Stage 3," but a $10 \mathrm{~s}$ punishment period was inserted where mice had to wait to initiate a new trial if they chose to lick longer than the set criterion in response to the designated $\mathrm{S}^{-}$odor. Typically, mice were initially trained using $2 \%$ ethyl acetate as $\mathrm{S}^{+}$and water as the $\mathrm{S}^{-} . \mathrm{S}^{+}$and $\mathrm{S}^{-}$individual trials were presented in random order with the restriction that there be an equal number of each in each session of 20 trials, which was defined as a block. Mice were provided the opportunity to complete 10 blocks of 20 trials, or a maximum of 200 trials per daily session. As originally defined by Slotnick and Restrepo (2005), the percentage of correct responses per trial was determined by the following formula: $\%$ correct responses $=[($ HITs + Correct Rejections $) / 20] \times 100$, where a HIT was defined as a criterion response in the presence of $\mathrm{S}^{+}$and a Correct Rejection (CR) was a failure to make a criterion response in the presence of $\mathrm{S}^{-}$. A miss was defined as a failure to make a criterion response in the presence of $\mathrm{S}^{+}$, and a false alarm (FA) was a criterion response in the presence of $\mathrm{S}^{-}$.

Statistical analyses. For the analysis of body weight and serum glucose, a two-way ANOVA was applied with either a blocked factorial (repeated measure) design using treatment and time as factors or a randomized design using genotype and diet type as factors. Post hoc tests for multiple comparisons were performed with a Bonferroni's correction. All graphed values are reported as the mean $\pm \mathrm{SEM}$, and the values for $F$, degrees of freedom (df), sample size $(n)$, probability $(p)$, or $\chi^{2}$ are incorporated into the figure for ease of text reading. Statistical significance was determined at the $95 \%$ confidence level $(\alpha \leq 0.05)$ unless otherwise noted. Post hoc analyses of all mean-wise comparisons were indicated with lettering, whereby means noted with the same letter are not significantly different. To highlight the comparison of control means with that of treatment means, bars with varying $p$ 
values were also indicated. The $F_{\max }$ test was used to confirm equal variances before performing the planned statistical metric so that differences in sample size did not bias the analysis.

Because the factor of genotype upon circuitry and OSN abundance had been previously determined for $\mathrm{Kv}_{1.3^{-/-}}$mice (Biju et al., 2008), the analyses for anatomical data were narrowed to within genotype to determine the impact of diet alone. Therefore, multiple-comparison testing for anatomical data was predominantly performed using an one-way ANOVA with diet as the factor. Student's $t$ tests were applied for comparison of normally distributed, two-sample population studies and also a modification of such (arcsine transformation) for ratio values (such as Western blot analysis, densitometry quantification). For the analysis of EOG dose-response curves, two-way ANOVA was applied with a mixed blocked factorial design (repeated measure) with diet and concentration as the two factors. For the analysis of olfactometry behaviors, two-way ANOVA was applied with a blocked factorial design (repeated measure) with genotype and time or diet and time as the two factors. In instances where correct hits are plotted within genotype across three different diets, graphs were plotted separately (CF/MHF or $\mathrm{CF} / \mathrm{HF}$ ) for visual clarity, but statistical analyses were collectively applied using diet (CF, MHF, HF) and time (blocks) as factors. Finally, $2 \times 3$ contingency comparisons were analyzed by $\chi^{2}$ for the percentage of success to meet operant behaviors or reversal learning at the $95 \%$ confidence level.

\section{Results}

Diet- and genetic-induced obesity

$\mathrm{WT}$ and $\mathrm{Kv} 1.3^{-1-}$ male mice were maintained on control Purina Chow (CF, 13.5\% fat), a moderately high-fat diet (MHF; $32 \%$ ), or a high-fat diet (HF; $60 \%$ ) from the time of weaning. Mice with a disruption of the melanocortin 4 receptor to induce late-onset genetic obesity (Huszar et al., 1997; Tucker et al., 2008), $M C 4 R^{-1-}$ and $M C 4 R^{-1-} / K v 1.3^{-1-}$, were maintained on CF diets. Progressive body weight gain due to increased adiposity (Tucker et al., 2008, 2012a, b) in response to the fatty diet or genetic mutation was monitored weekly for 24 weeks (Fig. $1 A-D$ ). Weight gain in $K v 1.3^{-1-}$ mice on MHF diets was significantly less than that of WT mice (Xu et al., 2003; Tucker et al., 2012a, b) (Fig. 1 A, C,D); however, at 60\% fat in the diet (HF diet), the $K v 1.3^{-l-}$ mice had a delayed increase in body weight over time (Fig. $1 B$ ) that remained significantly less than that of their WT counterparts. The fasting glucose in the $K v 1.3^{-1-}$ mice was hypoglycemic independent of diet (Fig. $1 E$ ). Moreover, IPGTT indicated that CF and HF fed $K v 1.3^{-1-}$ mice were able to clear a glucose challenge significantly faster than that of WT mice (Fig. $1 F$ ).

\section{Fatty diets reduce OSN abundance and bulbar projections}

To determine whether DIO or genetic-induced obesity had an impact on OSN abundance or axonal projection, we examined the dorsal M72 glomerulus in OB whole mounts in WT, $K v 1.3^{-/-}$, $M C 4 R^{-1-}$, and $M C 4 R^{-1-} / K v 1.3^{-1-}$ mouse lines (see Materials and Methods) expressing the M72-IRES-tau-LacZ transgene
B WT
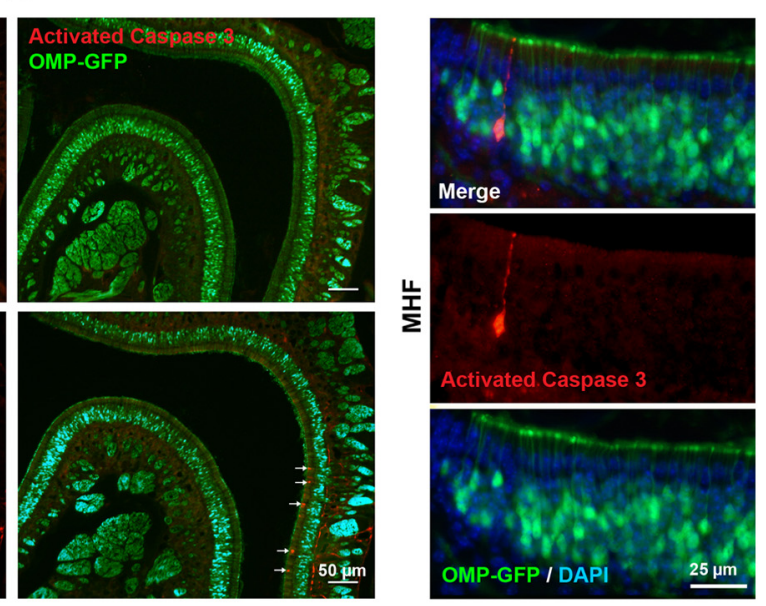

WT
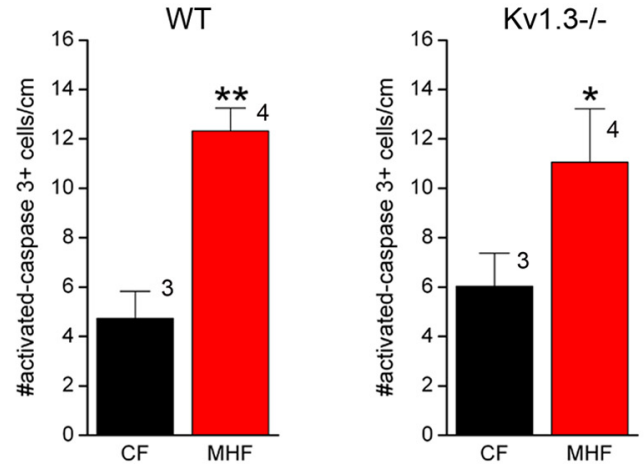

Figure 6. Maintenance on a MHF diet simultaneously induces OSN apoptosis and basal cell proliferation in the MOE. $A$, RepreTUNEL-positive cells, or (middle, right) activated caspase-3-positive cells in WT and Kv1.3 ${ }^{-1-}$ mice, respectively. Student's $t$ test where sample size represents number of mice/treatment using 10 sections/mouse. ${ }^{*} p \leq 0.05$. ${ }^{* *} p \leq 0.01$.

(Zheng et al., 2000). Mice challenged with a fatty diet yielded a prominent phenotype. The density of the axonal projections from the M72-expressing OSNs was dramatically reduced for both WT and $K v 1.3^{-1-}$ mice on the MHF diet (Fig. $2 A, B$ ), albeit the lack of significant fat deposition in the $K v 1.3^{-1-}$ mice (Tucker et al., 2012a). There was a differential response to the HF diet across genotypes, whereby the M72 axonal projections in WT mice were clearly reduced but those in $\mathrm{Kv}_{1.3^{-1-}}$ mice were of similar density as that of CF-maintained mice (Fig. 2A,B). We did not observe a modification in the number of glomeruli per half bulb or in the approximate topographical position of the projection as a result of either DIO or genetically induced obesity (Figs. $2 C$ and $3 A, B$ ). The cross-sectional area of the M72 medial and lateral glomeruli of WT mice was smaller in both MHF- and HF-treated animals (Fig. $3 C$ ). The genetically obese mice had M72 glomeruli that were intermediate in size between that of CFversus MHF- or HF-treated mice but were only significantly different from controls for lateral glomeruli. In the MHF-challenged $K v 1.3^{-1-}$ mice, there was a significant reduction in the size of the lateral but not medial M72 glomerulus, and there was no significant reduction in size of either glomerulus for HF-challenged $K v 1.3^{-1-}$ mice (Fig. 3D). The genetically obese mice in the $K v 1.3^{-/-}$background (Kv1.3 $3^{-1-} / M_{C} 4 R^{-/-}$double mutants) were also not statistically different from WT for either glomeruli. 
A

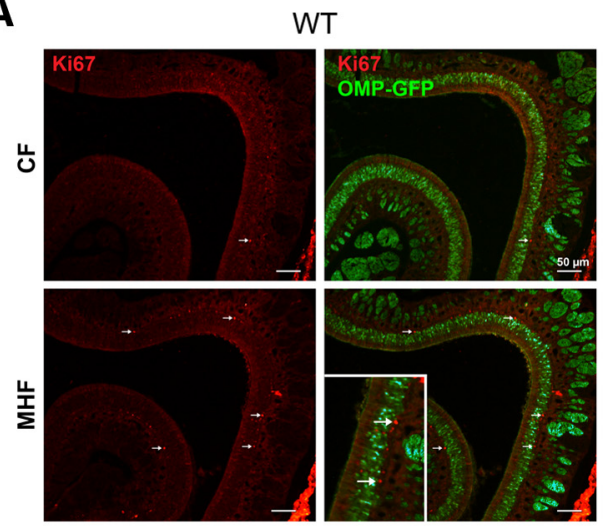

B

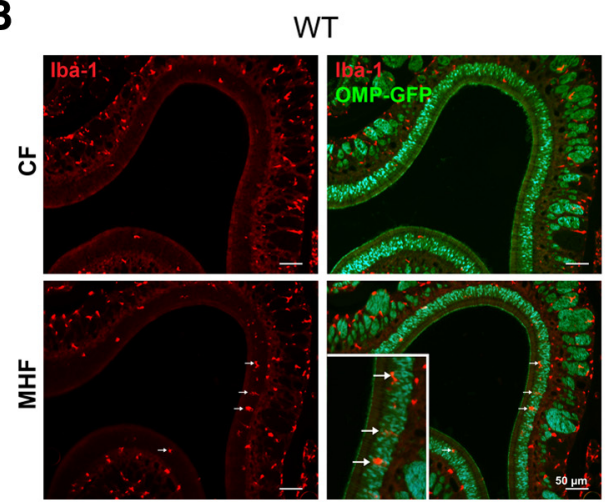

C

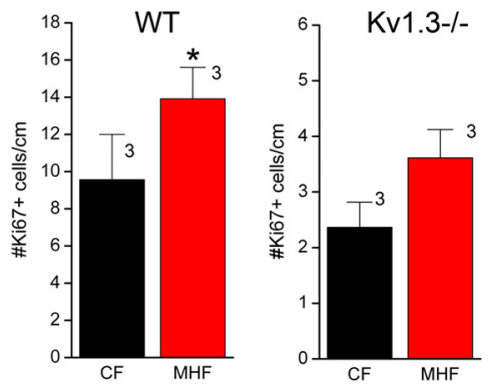

D

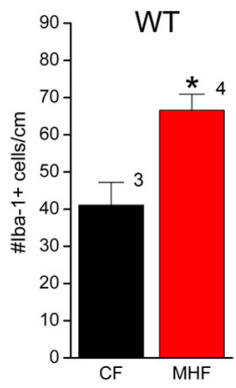

Figure 7. Maintenance on a MHF diet simultaneously induces basal cell proliferation in the MOE while activating microglia. $\boldsymbol{A}$, Representative photomicrographs of the MOEs of OMP-GFP littermates (OMP-GFP; olfactory marker protein; green) that were maintained on CF versus MHF diet for 6 months and then (left) labeled with the proliferation marker, anti-Ki67 (red). Right, Dual channel. Arrows indicate Ki67-positive cells. Inset, Higher magnification indicates positive basal cell labeling. $\boldsymbol{B}$, Same experimental paradigm as $\boldsymbol{A}$ but labeled with the microglial/macrophage marker, ionizing calcium binding adaptor protein 1, lba- 1 (red). Inset, Higher magnification indicates Iba-1-positive cells. $C$, Bar graph of the mean \pm SEM number of Ki67-positive cells after maintenance for 6 months on CF (black bar) or MHF (red bar) diet. Student's $t$ test where sample size represents number of mice/treatment using 10 sections/mouse. ${ }^{*} p \leq 0.05$. ${ }^{* *} p \leq 0.001$. D, Bar graph, sample size, and statistical analysis as in $C$ but for lba-1-positive microglial cells.

These data indicate that modified fatty diet, as opposed to strictly adiposity, is significantly altering defined circuitry by reducing the size of the synaptic target and axonal projections, particularly for the lateral glomerulus.

We reasoned that whether there was a reduction in the size of an axonal projection with fat feeding, there should be fewer neurons. Indeed, we found that WT mice maintained on the MHF diet lost 55\% of their M72-expressing OSNs (5988 \pm 572 neurons $=\mathrm{CF}$ diet, $n=12$ mice vs $2710 \pm 664$ neurons $=$ MHF diet, $n=9$ mice) (Figure $4 A, C$ ) as did $\mathrm{Kv} 1.3^{-1-}$ mice on the MHF diet that lost 51\% (5894 \pm 405 neurons $=$ CF diet, $n=4$ mice vs $2905 \pm 332$ neurons $=$ MHF diet, $n=4$ mice) (Fig. $4 B, D)$. In parallel to differential projection density across genotypes in response to HF diet, WT mice maintained on HF diet lost $51 \%$ of their M72-expressing OSNs $(2934 \pm 221$ neurons $=$ HF diet, $n=$ 4 mice) (Fig. $4 C$ ), whereas Kv1.3 $3^{-1-}$ mice exhibited a resistance to the loss of neurons $(6056 \pm 454$ neurons $=$ HF diet, $n=4$ mice) (Fig. $4 D$ ), representing only a $3 \%$ change compared with

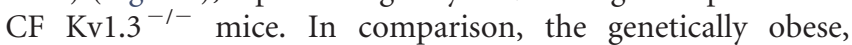
$\mathrm{MC}^{-1-}$ mice did not exhibit a loss of M72-expressing OSNs $(6052 \pm 1098$ neurons, $n=5$ mice $)$ nor did the Kv1.3 ${ }^{-/-}$/ MC4 $\mathrm{R}^{-1-}$ mice $(6053 \pm 721$ neurons) (Fig. $4 A-D)$. Because odor enrichment is known to influence OSN survival and production of newborn neurons in the OB (Watt et al., 2004; Caval-

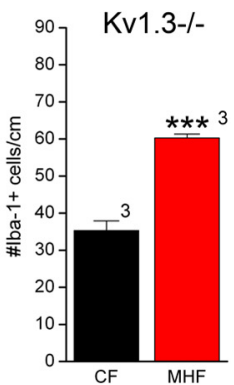

lin et al., 2010; Rochefort et al., 2002), for 6 months we hung MHF chow in a tea ball in the home cage of WT mice so that mice would be exposed to the odor, but not the fat, of the MHF chow. These mice exhibited a mean M72-OSN abundance (8460 \pm 226 neurons, $n=4$ mice) that was not significantly different from the control group (Fig. 4C). These data also suggest that the fat in the diet, rather than increased adiposity (Tucker et al., 2008, 2012a), attributed to a reduction in the abundance of M72 OSNs. For parallel support of this contention, we plotted OSN abundance versus body weight (data not shown) and ran a Spearman correlation that demonstrated poor correlation and no statistical difference $(r=-0.3102$; $p \geq 0.05, n=38$ ). The differential mechanism by which the HF-maintained $\mathrm{Kv}_{1.3^{-1-}}$ mice fail to exhibit OSN loss is not understood.

We next challenged a mouse model that identifies all mature OSNs, or the $O M P-G F P$ transgenic line, to test whether many types of OR-expressing OSNs may be lost after maintenance on an MHF diet (Fig. 5). Within the endoturbinate IIb, there was a $25 \%$ reduction in the number of mature OSNs after a 6 month challenge with MHF diet (Fig. $5 A, B$ ). Within the ectoturbinate 2 and the septum, more modest reductions in mature OSNs were observed that did not reach statistical significance. As a control, we confirmed that measured MOE thickness across the three regions was not linked to diet for either genotype (Fig. 5C,D). Given that mature OSNs express the olfactory transduction machinery at the ciliary surface, we anticipated that a dietinduced reduction in OSN abundance should be linked to a reduction in G-protein and GPCR concentration in WT mice. Our biochemical results presented in Figure 5E, $F$ demonstrate that MHF diet causes a significant loss in the expression of the G-protein $G_{\alpha o l f}$ and the odor receptor MOR28 compared with those from CF-treated littermates. Because $\mathrm{Kv} 1.3^{-1-}$ mice express more ciliary membrane with increased expression of signal transduction machinery (Biju et al., 2008), we did not have a prediction for their response to chronic MHF treatment. Our biochemical results presented in Figure $5 F$ demonstrate a measured resistance to loss of $\mathrm{G}_{\alpha \mathrm{olf}}$ and MOR28 proteins.

\section{Effect of DIO on the apoptosis and proliferation of the MOE}

To determine whether the loss of OSNs was a result of a reduced proliferative activity or an increased death of neurons, we quantified the abundance of proliferative and apoptotic cells in the MOE using OMP-GFP fat-challenged mice. MHF diet caused a significant increase in activated caspase- 3 expressing cells (Fig. $6 A$ ) as quantified in both WT and $\mathrm{Kv} 1.3^{-1-}$ mice (Fig. $6 C$, middle, right). At high magnification, we could distinguish that some of the OSNs labeled with caspase-3 antibody in the MHF diet group were not $\mathrm{OMP}^{+}$(Fig. 6B), as also observed by Ohsawa et al. (2008) for control mice. An augmentation of apoptotic cells 
was therefore confirmed by an increased number of TUNEL ${ }^{+}$ cells (Fig. $6 C$, left). TUNEL ${ }^{+}$cells were detected both in the apical sustentacular cells and in the median OSN layers. Using the proliferation marker Ki67, we unexpectedly measured a significant increase in $\mathrm{Ki}^{+}{ }^{+}$cells after an MHF diet (Fig. 7A) that reached statistical significance in the WT but not Kv1. $3^{-1-}$ mice (Figure 7C). These cells were progenitor basal cells near the lamina propria and, as expected, did not colabel with the $\mathrm{OMP}^{+}$cells. Together, these data suggest that the MHF diet may increase the kinetics of regeneration in the olfactory epithelium by increasing the apoptosis of the neuronal population while also increasing mitosis of the progenitor basal cells. Last, because the dietary effect was not pronounced enough to affect MOE thickness (Fig. $5 C, D)$, we quantified the extent of anticipated inflammation using an antisera against the ionized calcium-binding adaptor molecule, Iba-1. Using Iba-1 as a marker for microglia and macrophages, we observed a significant increase in Iba- ${ }^{+}$cells in both WT and $K v 1.3^{-1-}$ mice (Fig. $7 \mathrm{~B}, \mathrm{D}$ ). These results indicate an increase in proinflammatory cells following a MHF diet challenge.

Odorant response is reduced after maintenance on fatty diet Because there was a significant loss of axonal projections to the M72 glomerulus as well as a reduction in M72-expressing OSNs in response to fatty diets in WT mice, we reasoned that there should be a measurable loss of odorant responsiveness to acetophenone, a known ligand for the M72 receptor (Feinstein et al., 2004). The odor-evoked electrical response of the main olfactory epithelium was significantly less in mice that had been challenged to HF diet for 6 months compared with that in CF mice as determined by electro-olfactogram (EOG) recordings (Fig. 8A). This reduction in EOG amplitude, which is proportional to the number of activated neurons, is consistent with our findings of a decreased OSN abundance following a HF diet challenge. EOG rise time, latency to response, and event recovery were not significantly different across diet (data not shown), suggesting lack of dysfunction in transduction or adaptation of the odor response. We then measured responsiveness across a dose-response curve whereby sensitivity was significantly reduced across the dynamic range of the relationship for a population of recorded EOGs (Fig. $8 B$ ). Our data therefore collectively suggest that there may be both structural and odor responsivity modifications in the olfactory system in response to fatty diets, which might be discernible as a loss of olfactory-based behavior.

\section{Olfactory discrimination and odor threshold after maintenance on fat-based diets}

Mice were trained with a "go no-go" operant conditioning paradigm to recognize an odorant using a computerized, 8 channel liquid dilution olfactometer (Knosys Olfactometer; Fig. 9A,B). Mice were provided the opportunity to complete 10 blocks of 20 trials, or a maximum of 200 trials per daily session (Fig. 9C). As originally defined by Slotnick and Restrepo (2005), the percentage of correct responses per trial was determined by the following formula: \% correct responses $=[($ HITs + Correct Rejections $) /$ 20] $\times 100$ where a hit was defined as a criterion response in the presence of $\mathrm{S}^{+}$and a correct rejection (CR) was a failure to make a criterion response in the presence of $\mathrm{S}^{+}$. A miss was defined as a failure to make a criterion response in the presence of $\mathrm{S}^{+}$, and a false alarm (FA) was a criterion response in the presence of $\mathrm{S}^{-}$. A summary plot of correct hits for 200 trials performed by the control fed, WT mouse (CF WT) shown in Figure 9 C is shown in Figure $9 D$, whereby initial performance (first 6 blocks) is im-
A

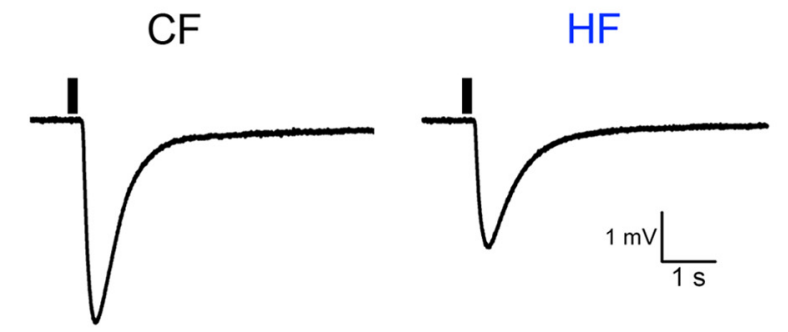

B

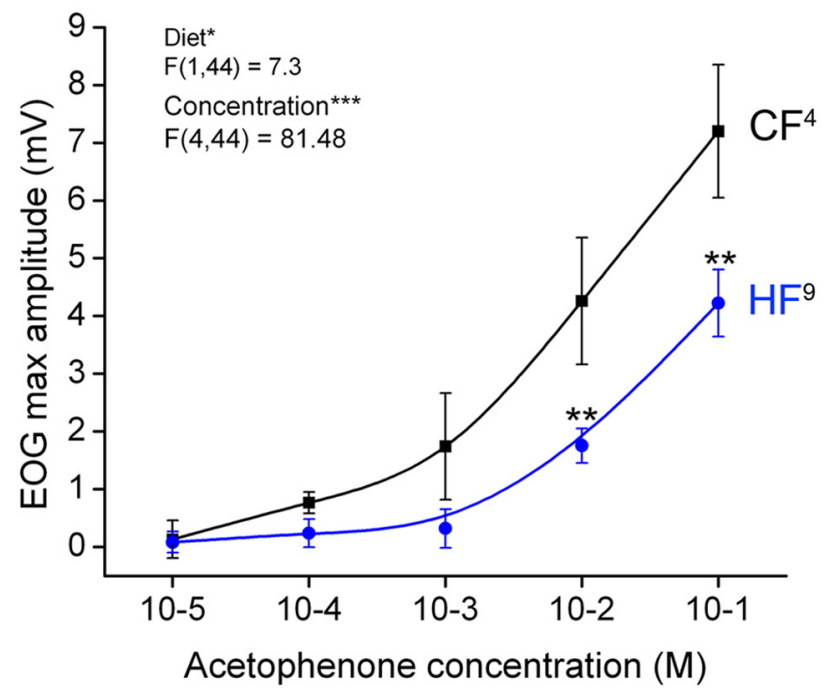

Figure 8. Maintenance on a $\mathrm{HF}$ diet causes a reduction in EOG amplitude in response to the M72 ligand, acetophenone. $\boldsymbol{A}$, Representative EOG recordings taken from the dorsal surface of endoturbinate IIb and III acquired from a mouse weaned to (left) CF versus (right) HF chow. A total of $10^{-2} \mathrm{M}$ of acetophenone was applied at the bar for $100 \mathrm{~ms}$. $\boldsymbol{B}$, Line graph of the mean \pm SEM EOG amplitude for CF versus HF maintained mice recorded as in $\boldsymbol{A}$ in response to varying concentrations of odorant. Two-way ANOVA, mixed blocked factorial design, where sample size represents number of recordings (one per mouse). ${ }^{*} p \leq 0.05 .{ }^{* *} p \leq 0.01 .{ }^{* *} p \leq 0.001$.

proved over time, and the mouse achieves criteria of $80 \%$ correct hits by the end of the experiment (blocks 6-10). This was representative of the typical acquisition of operant behavior in CF WT mice and the format of calculated graphs for subsequent figures. Mice that performed two sequential days ( 400 trials) $>80 \%$ correct hits were considered trained to criteria (solid line), or confirmed detection between two stimuli, $\mathrm{S}^{+}$and $\mathrm{S}^{-}$, and $50 \%$ correct response (dashed line) was defined as performance by chance alone. Correspondence with other olfactometry researchers had indicated that valve vibration could be a source of offtarget cues for discrimination. After dampening of our solenoid valves with supersoft polyurethane rubber (Grainger Industrial Supply), we performed several control experiments in which animals trained to criteria were then monitored for discrimination when the valves were activated but when C-flex tubing was detached from delivery to the mixing chamber (Fig. 9E). We performed this type of experiment to control for mechanical sensation for both CF and HF mice and demonstrate a representative trial for that of a WT mouse on a CF diet in Figure 9E. In all mice sampled $(n=4)$, removal of the tubing from the valve resulted in the mouse falling to correct decisions that could be attributed to chance alone (50\% correct hits) and then immediately returning to pretest, criterion values upon reintroduction of the tubing. 
A

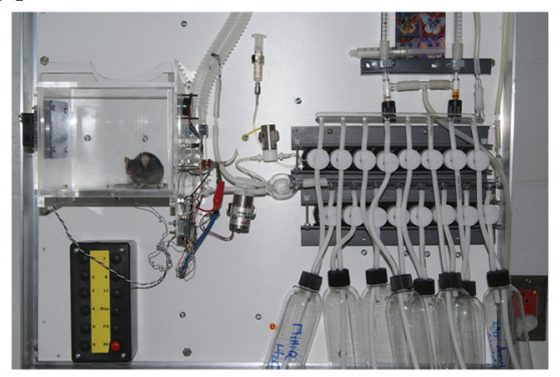

C

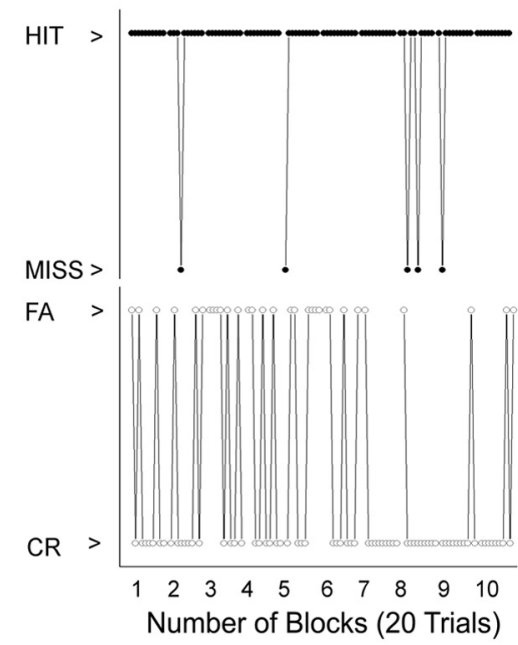

B

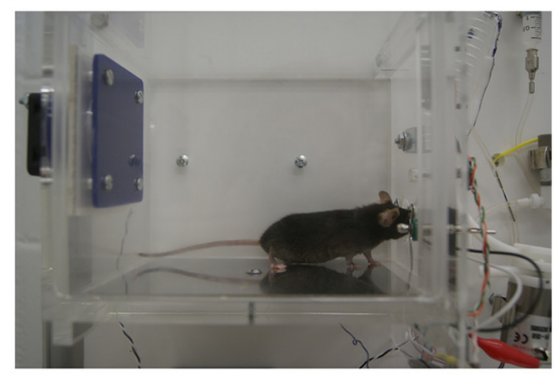

D

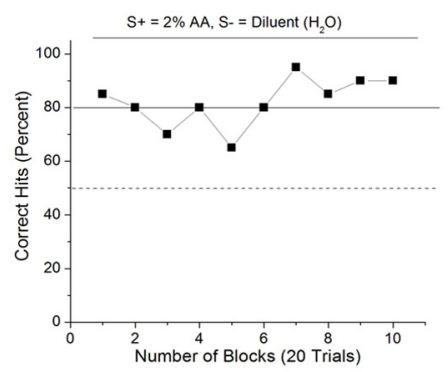

E

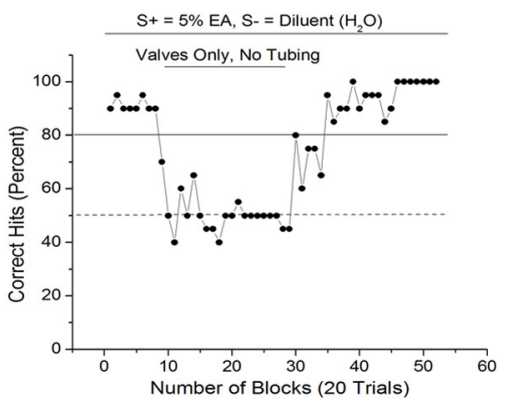

Figure 9. Mice can be trained in a liquid-based, computerized olfactometer to determine olfactory discrimination using a "go no-go" operant conditioning paradigm. $\boldsymbol{A}$, Photograph of a mouse in the operant chamber where it is trained to recognize an odorant paired with a water reward in conjunction with a computerized, 8 channel liquid dilution olfactometer (Knosys; for details, see Materials and Methods). $\boldsymbol{B}$, Insertion of the mouse's snout into the odor-sampling port initiated training for correct licking behavior toward a positive odor cue $\left(S^{+}\right)$and correct rejection behavior toward a negative odor cue $\left(S^{-}\right)$. C, Example line graph of a typical daily training session in which 20 random trials (defined as a block) are delivered in the form of an equal number of $S^{+}$ and $S^{-}$odor cues to the mouse for correct decisions that are paired with a water reward. A HIT is defined as correct licking behavior in response to $S^{+}$, and a CR (correct rejection) is defined as a correct withdrawal of the snout in response to $S^{-}$. A MISS is defined as a withdrawal of the snout in the presence of $S^{+}$, and a FA (false alarm) is defined as an incorrect licking behavior in response to $S^{-} . D$, Line graph of the representative performance of a WT mouse maintained on control food (CF) diet whereby each data point represents the percentage of correct hits per block (20 trials) as tabulated in Materials and Methods. Generated from data in C upon the first initiation of the mouse to operant conditioning. AA, Amyl acetate. $\boldsymbol{E}$, Line graph of the representative performance of a WT mouse previously trained in operant conditioning whereby the odorant delivery tubes were disconnected (Valves Only, No Tubing) to control for any mechanical cues that the mouse may be using for task performance. EA, Ethyl acetate. Data points calculated as described in C, D. D, E, Dashed line indicates $50 \%$ correct hits (performance by chance alone); solid line indicates $80 \%$ correct hits (performance at defined criteria).

After maintenance on a CF versus HF diet for 26 weeks, WT and $\mathrm{Kv} 1.3^{-1-}$ mice were introduced to olfactometry training. The rate at which mice became proficient and could perform operant behaviors was influenced by diet treatment (Fig. 10). The number of necessary training trials in the "Stage 3" odor reinforcement paradigm (see Materials and Methods), which mice required before advancing to operant conditioning, significantly increased for mice maintained on the fatty diets independent of genotype (Fig. 10A). Both WT and $K v 1.3^{-1-}$ mice maintained on MHF or HF diets were therefore slower to correctly learn that an odor was paired to a water reinforcement (Fig. 10A). In particular, $43 \%$ of WT and $K v 1.3^{-/-}$mice challenged on MHF diets exhibited a failure to operant learn compared with a $94 \%-100 \%$

success rate for their CF littermates (Fig. $10 \mathrm{~A}$, inset). After they acquired this association, we then compared olfactory performance across genotype for a simple discrimination task of 5\% ethyl acetate versus diluent (water). Upon first introduction to the operant conditioning paradigm, WT mice first achieved $80 \%$ correct hits after the completion of 4 or 5 blocks, or 80-100 trials, whereas $K v 1.3^{-1-}$ mice typically required $8-10$ blocks, or 160-200 trials to achieve the same level of correct hits (Fig. 10B). Once olfactory performance had reached criteria ( $80 \%$ correct hits), performance across genotype was largely overlapping for this simple discrimination task. Both WT and $K v 1.3^{-1-}$ mice maintained on MHF diet (Fig. 10C,D) exhibited increased ability during the acquisition phase of the operant task, but not significantly different performance after the first day of training (200 trials, or 10 blocks). WT mice maintained on HF diet, however, rarely achieved $80 \%$ correct hits and frequently performed by chance alone at the $50 \%$ level, whereas $K v 1.3^{-1-}$ mice challenged with the HF diet had higher rates of percentage correct hits and learned the operant conditioning paradigm at a faster rate than those maintained on the CF diet (Fig. $10 E, F)$. Collectively, these data indicate that fat in the diet initially slows acquisition of rewarded learning independent of genotype; however, once mice are performing operant conditioning behavior at criteria, higher fat accentuates olfactory discrimination in $K v 1.3^{-1-}$ mice whereby it decreases olfactory discrimination in WT mice.

\section{Reversal learning after maintenance on fat-based diets}

After the learned discrimination between ethyl acetate versus diluent (water), we introduced a second odorant (acetophenone) in place of the $\mathrm{S}^{-}$water cue. We chose acetophenone because both odorant molecules have the structural similarity of the adjacency of a ketone and methyl group, but also because acetophenone is a known ligand for the M72 odorant receptor (Feinstein et al., 2004). For control fed animals, upon introduction of acetophenone as the $\mathrm{S}^{-}$stimulus, WT mice fell to a discrimination level approximating chance alone $(50 \%-60 \%)$ for $1-3$ blocks ( $20-60$ trials) before they were able to regain a performance $>80 \%$ correct hits, whereas $K v 1.3^{-1-}$ mice stayed $>80 \%$ correct hits during the change in stimulus identity. HF mice followed these same respective patterns, only with the HF WT mice maintaining a lower overall correct hits and the HF $K v 1.3^{-1-}$ mice maintaining a higher overall correct hits than their CF counterparts (data not shown). After the successful training of the six groups of mice on these odor versus odor discrimination protocols, we tested the ability 
of diet-modified and transgenic mice to relearn a reinforced task if the $S^{+}$stimulus was switched to the $\mathrm{S}^{-}$stimulus (Doucette et al., 2011). Such reversal learning examines behavioral flexibility or executive function when the reward contingency is reversed, for example (Schoenbaum et al., 2002a, b). WT mice on CF diet typically had the ability to successfully reversal learn within 10 blocks, or 200 trials, whereas the Kv1.3 ${ }^{-/-}$mice took $30 \%$ longer (Fig. 11A,F). Maintenance on a MHF or HF diet severely inhibited WT mice from reversal learning; only 2 of 5 mice tested were able to complete the $\mathrm{S}^{+}$ for $\mathrm{S}^{-}$stimulus switch if maintained on MHF diet, and only 1 of 6 mice was similarly successful if maintained on HF diet (Fig. $11 F$, inset). This was not the case for Kv1.3 $3^{-1-}$ mice challenged with the MHF diet, where $50 \%$ of mice tested for reversal learning were able to complete the reversal and for HF diet treatment, 100\% were able to complete the reversal (Fig. $11 E, F$, inset). Interestingly, we discovered, through repeated reversal learning challenges, that $K v 1.3^{-/-}$mice only displayed behavioral inflexibility with the first reversal learning challenge, but not on subsequent trials as clearly visualized in Figure $11 G-J$. These data indicate that, beyond changes in olfactory discrimination, increased adiposity, rather than fat in the diet, promotes behavioral inflexibility, whereas deletion of Kv1.3 gene slows, but does not prevent, executive function responsible for relearning a rewarded task.

\section{Olfactometry performance after withdrawal of the fat-based diet}

We questioned whether the effects of fatty

diet were plastic or reversible. We thereby placed the Knosys trained, WT HF mice on a "diet" of CF for 5 months and then reexamined their olfactometry performance. The mean reduction in body weight after "dieting" was $-23 \%$ (obese weight before $\mathrm{CF}$ diet $=46.9 \pm 1.8 \mathrm{~g}$; reduced weight after the $\mathrm{CF}$ diet $=$ $36.3 \pm 1.0 \mathrm{~g}$ ). By comparison, the mean adult body weight of $\mathrm{CF}$ WT mice was $28.4 \pm 0.6 \mathrm{~g}$, and only changed by $+5 \%$ during this same 5 month interval. The fasting glucose in these mice concomitantly dropped from $256 \pm 21.8 \mathrm{mg} / \mathrm{dl}$ to $129 \pm 3.3 \mathrm{mg} / \mathrm{dl}$, within range of the constantly maintained CF WT mice (122.8 \pm $7.9 \mathrm{mg} / \mathrm{dl}$ ) and within normal fasting levels reported for C57BL/6J animals (Andrikopoulos et al., 2008). Control mice that had been maintained on the CF diet throughout the study and had a similar 5 month intermission from working in the Knosys were first retested for retention of operant behavior. Control mice had no difficulty in retaining discrimination (Fig. 12A). This is in marked contrast to the three HF mice that received the "diet" by switching to CF chow for 5 months. One of the three mice could no longer perform the operant behavior and did not finish multiple odor reinforcement trials (Stage 3 ) offered daily for 2 weeks. The remaining mice finished odor reinforcement trials but pernoted. ${ }^{*} p \leq 0.05 .{ }^{* * * *} p \leq 0.0001$.

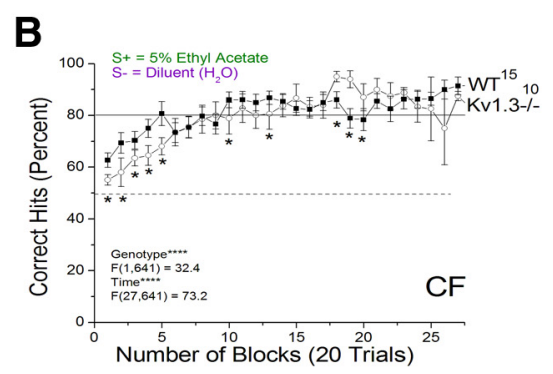

D

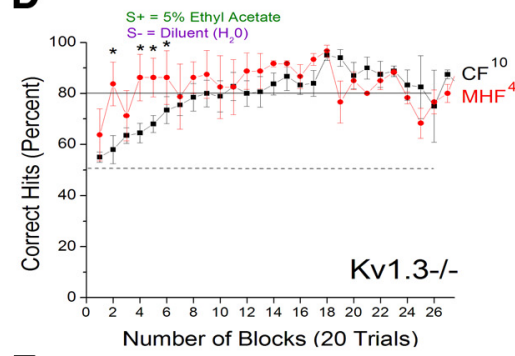

$\mathbf{F}$

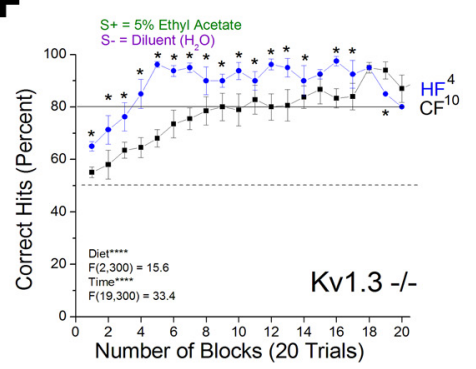

Figure 10. Fatty diets slow acquisition of operant conditioning behaviors independent of genotype and decrease olfactory discrimination. $A$, Bar graph of the mean \pm SEM number of trials of odor reinforcement learning necessary for successful performance in an operant conditioning paradigm. Dashed line indicates mean number of trials for WT CF mice. Two-way ANOVA where

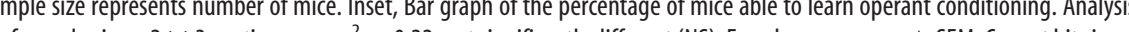
performed using a $2 \times 3$ contingency, $\chi^{2}=0.22$, not significantly different (NS). Error bars are mean \pm SEM. Correct hits in an odor versus diluent (water) paradigm comparing $(\boldsymbol{B})$ the effect of genotype while on $C F$ diet, $(\boldsymbol{C}, \boldsymbol{D})$ the effect of MHF diet in $(\boldsymbol{C})$ WT mice, and $(\boldsymbol{E}, \boldsymbol{F})$ the effect HF diet in $(\boldsymbol{E})$ WT and $(\boldsymbol{F})$ Kv1.3 $3^{--}$mice. Lines indicate performance resulting from

formed very poorly or at the same level of correct hits as when maintained on the HF chow (Fig. 12B). These data indicate that the physiological effect of the HF chow on olfactory learning and discrimination may be long-lasting or potentially not reversible. An examination of the brains of these animals revealed that the HF mice that were "dieted" by switching to CF chow did not regain axonal projections to the M72 glomerulus, whereas the agedmatched continuous CF chow maintained animals had normal axonal densities (Fig. 12C).

\section{Discussion}

In the present study, we selectively discovered that the high-fat diet, independent of the degree of adiposity, can impact the general neuroarchitecture of the olfactory system and concomitantly lead to slowed learning acquisition of a reinforcement task leading to operant conditioning behaviors. Moreover, in WT mice made obese through high-fat diet, there is a clear reduction in olfactory discrimination in which obese mice have at least a $20 \%$ reduced performance of correct decisions compared with mice maintained on a CF diet. Such reduction in sensory performance, which is precipitated by a chronic increase in fat in the diet, may 
A

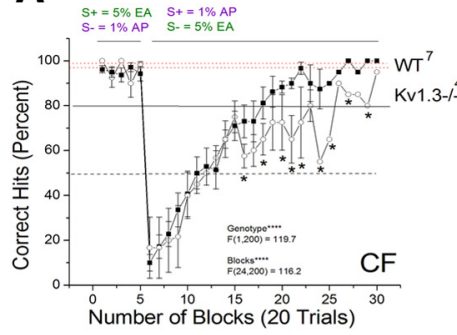

D

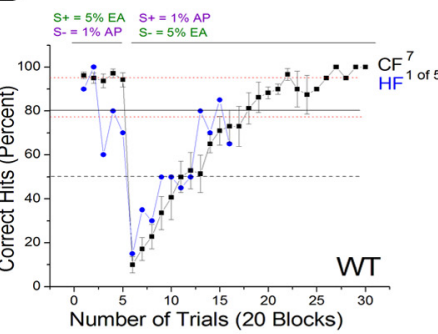

G

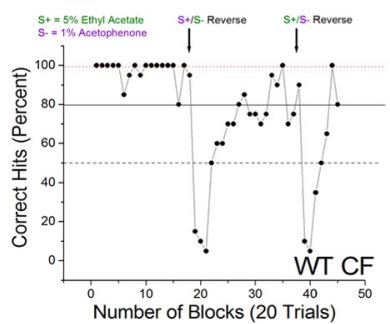

B

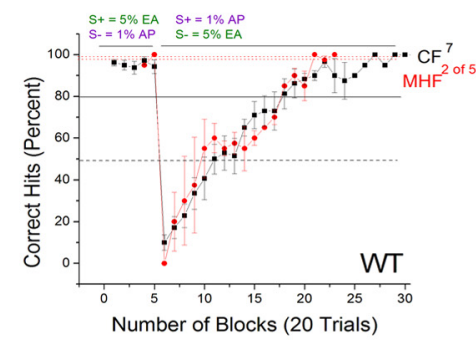

E

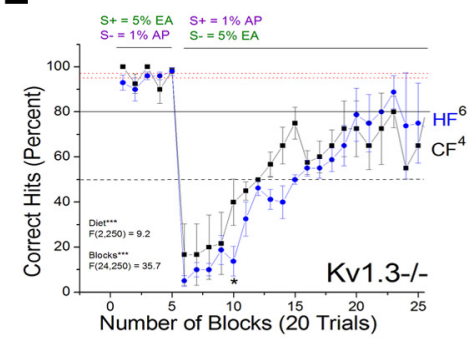

H

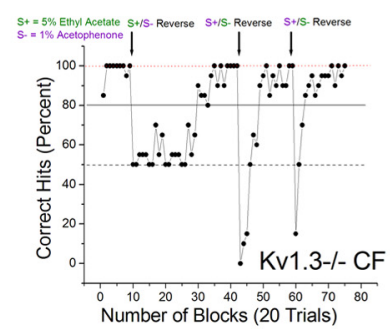

C

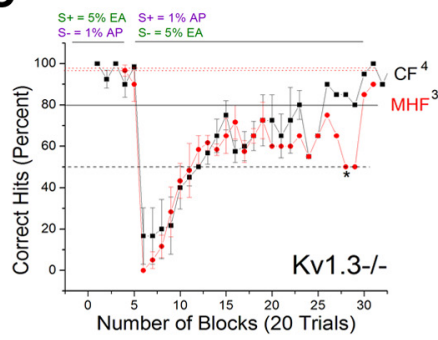

F

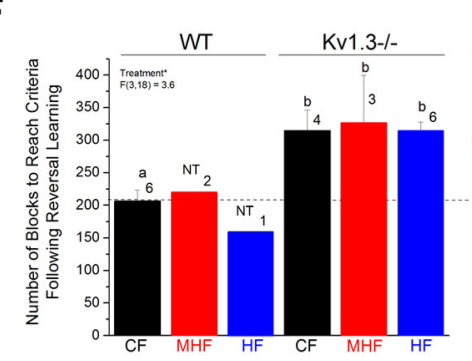

Figure 11. Fatty diet causes behavioral inflexibility as exemplified in failed odor reversal-learning paradigms for WT but not $K v 1.3^{-/-}$mice. Correct hits in an odor versus odor, reversal learning paradigm (where $\boldsymbol{S}^{+}$and $\boldsymbol{S}^{-}$are switched) comparing $(\boldsymbol{A})$ the effect of genotype while on (F diet, $(\boldsymbol{B}, \boldsymbol{C})$ the effect of MHF diet in $(\boldsymbol{B})$ WT and $(\boldsymbol{C}) K_{v} 1.3^{-/-}$mice, and $(\boldsymbol{D}, \boldsymbol{E})$ the effect of HF diet in (D) WT and $(\boldsymbol{E}) K v 1.3^{-1-}$ mice. EA, Ethyl acetate; AP, acetophenone. Symbols, color coding and notations as in Figure 10. Red dashed line indicates mean correct hits before reversal learning, $S^{+} / S^{-}$reverse at the bar break or arroW. $\boldsymbol{D}$, Six WT mice were tested on HF diet, but only 1 animal had the ability to reversal learn (the one demonstrated in the plot). The same goes for $\boldsymbol{B}$, where only 2 of 5 WT mice tested on MHF diet were able to reversal learn. $\boldsymbol{F}$, Number of trials required to reachieve criteria after the induction of reversal learning. Inset, Bar graph of the percentage of mice able to reversal learn. Analysis performed using a $2 \times 3$ contingency, applying a $\chi^{2}$ as reported on graph. $\boldsymbol{A}-\boldsymbol{F},{ }^{*} p \leq 0.05$. ${ }^{* * *} p \leq 0.001$. ${ }^{* * *} p \leq 0.0001$. Not tested (NT). $\boldsymbol{A}-\boldsymbol{E}$, Blocked factorial ANOVA. $\boldsymbol{F}$, One-way ANOVA. G-J, Plots of the correct hits using a challenge with sequential reversal learning paradigms for $(\boldsymbol{G})$ WT and $(\boldsymbol{H}) K_{v} 1.3^{-/-}$mice maintained on $C$ F compared with $(\boldsymbol{I})$ WT

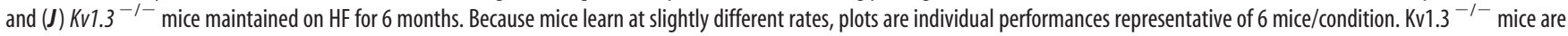
slower in acquisition of the initial (at first arrow of a series) reversal learning challenge, but their speed markedly improves upon subsequent reversal learning trials (subsequent arrows) compared with WT mice. Error bars are mean \pm SEM.

be linked to the observed loss of OSNs or just be one facet of likely multiple changes in different levels of the olfactory system attributed to the presence of fat. For example, we have previously demonstrated that chronic exposure to fat in the diet impairs action potential firing frequency and interspike intervals of mitral cells of the OB (Fadool et al., 2011), and we currently demonstrate a reduced EOG amplitude after maintenance on high fat.

The consumption of a hyperlipidemic diet reduced the abundance of OSNs and their axonal projection independent of body weight gain or accumulation in adiposity. The thin body morphology and resistance to DIO in the Kv1.3 ${ }^{-1-}$ did not prevent the loss of OSNs after MHF diet. When challenged with HF diet, however, Kv1.3 $3^{-1-}$ mice did not lose central projections, OSN abundance, nor did they have reduced olfactory discrimination. It would be interesting to speculate that the differential response to a diet of $60 \%$ fat $(\mathrm{HF})$ in the Kv1.3 $3^{-1-}$ mice could be contributed to a variable in the diet composition. Although both the MHF and HF have comparable protein levels (17\%-20\%), the MHF diet is both rich in carbohydrate (51\%) and fat $(32 \%)$, whereas the HF diet has a lower carbohydrate (20\%) but in- creased fat $(60 \%)$ over that of the MHF. Obesity attributed to disruption of the hypothalamic axis $\left(\mathrm{MC}^{-1} \mathrm{R}^{-1}\right)$ also did not contribute to anatomical disruption of the olfactory system in mice that were significantly obese but did not consume a diet high in fat $(13.5 \%)$. The fact that $\mathrm{Kv} 1.3^{-1-}$ mice do not exhibit a reduced olfactory performance after fat consumption could be contributed to decreased adiposity, differential serum chemistry, increased ability to clear glucose, or that they already have a heightened sense of olfactory ability before the high-fat challenge. Our previous work has shown that loss of Kv1.3 channel elicits a "Super-smeller" phenotype combined with increased expression of transduction machinery (i.e., olfactory receptors and $G_{\text {olf }}$ ), greater abundance of cilia per OSN, enhanced electrical excitability of mitral neurons, and early postnatal supernumerary projection of OSN to smaller targeted glomeruli (Fadool et al., 2004, 2011; Biju et al., 2008). Thus, the starting advantage of the Kv1.3 $3^{-l-}$ phenotype could circumvent functional losses of olfactory ability when maintained on a diet high in fat.

Although the cellular mechanisms underlying the dietinduced modifications we observed in the olfactory architecture 
A

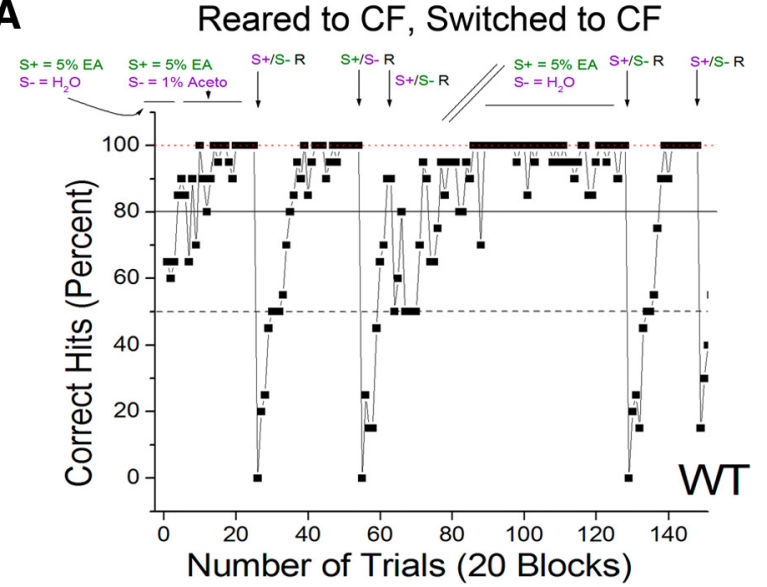

B

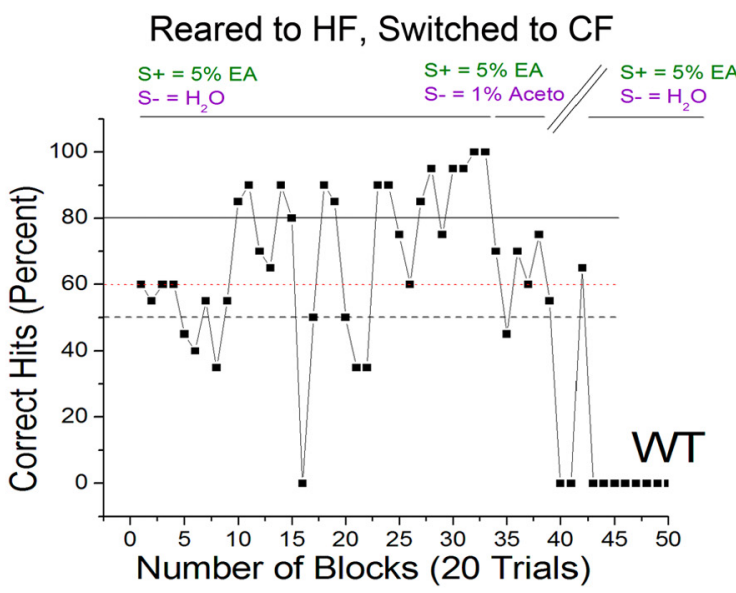

C

Reared CF / Switched CF Reared HF / Switched CF

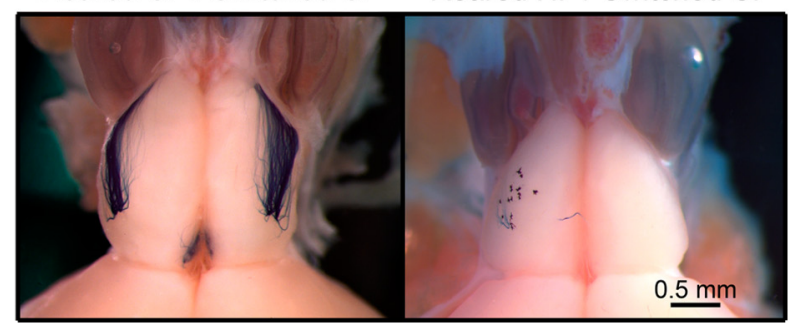

Figure 12. A fatty diet after weaning prevents odor-reversal learning and the recovery of odor discrimination despite return to CF diet, average fasting glucose level, and normal body weight. $A$, Plot of the correct hits for a representative WT mouse that was originally weaned to CF and then retained on $C F$ (Reared to $C F$, Switched to $C F$ ) for a 5 month period before rescreening (double hatch). B, A similar plot for a mouse that was weaned to HF and then "dieted" for a 5 month period on $C F$ (Reared to HF, Switched to CF) before rescreening (double hatch). Symbols and notations as in Figure 11. C, Whole-mount images revealing M72 axonal projections to the $O B$ from the mice "dieted" and trained as in $\boldsymbol{A}$ and $\boldsymbol{B}$, respectively.

are incompletely known, our findings suggest that proinflammatory responses are evoked in the MOE as they are in other organs in response to a changed energy consumption (Gregor and Hotamisligil, 2011). Moderate high-fat feeding drove an increase in the number of macrophages and in the degree of neuronal death induced by apoptosis, which led to reduced connections from the MOE to the OB. Cellular inflammation consequent to a high-fat diet has been described in peripheral tissues, such as liver or adipose tissue, and also within the CNS, including the cortex and hypothalamus. In the hypothalamus, high fat promotes macro- phage infiltration and microglia activation, which can lead to the release of proinflammatory interleukins and cytokines, such as IL-1 $\beta$, IL-6, and TNF $\alpha$ (De Souza et al., 2005; Moraes et al., 2009). Sultan et al. (2011) used transgenic models to demonstrate that TNF $\alpha$ can induce apoptotic death of OSNs. Activation of proinflammatory responses has been linked to the induction of insulin resistance, so it is interesting that our previous biochemical studies demonstrated such resistance in the $\mathrm{OB}$ in response to DIO (Marks et al., 2009; Fadool et al., 2011). Insulin resistance can lead to hyperglycemia as increased levels of insulin are required to clear plasma glucose (Martyn et al., 2008). The fact that the moderate $32 \%$ fat content diet in our study did not yet have significant effect on the basal fasted glycemic levels but that HF diet modulated ability to clear glucose (i.e., prediabetic) suggests that the neuronal modifications we observed are likely attributed to a combinatorial effect of plasmatic lipids, hormone resistance, and inflammatory responses.

Because ORs have been demonstrated to play an important role in OSN maturation and axon guidance (Feinstein and Mombaerts, 2004; Feinstein et al., 2004; Fleischmann et al., 2008), one could speculate that the postnatal fat feeding in our study precipitated an early deregulation of OR expression in OSNs that might thereby interfere with proper gene processing and targeting OSN axons to fixed glomeruli (Serizawa et al., 2003; Lewcock and Reed, 2004). We did not, however, observe a change in the number of M72 glomeruli or in their relative position after either MHF or HF diets, suggesting that a hyperlipidic diet does not affect axon targeting of OSNs, although it does modify expression of OR. This suggests that a modulation in OR expression level does not necessitate an altered axonal projection in all cases. Recent evidence has also emerged that apoptotic mechanisms and specific proteases can act during development to regulate proper axonal guidance of OSNs (Ohsawa et al., 2010; Cao et al., 2012; Cheng et al., 2011). For example, the Belluscio laboratory has demonstrated that disruption of FAF1, an apoptosis regulatory molecule in the MOE, causes misrouting of OSN axons to deeper layers of the OB (Cheng et al., 2011). A hyperlipidic diet that chronically induces a low level of apoptosis as evidenced by elevations in TUNEL and increased caspase-3 activity appears to drop levels of OMP-positive neurons without encroaching on a disruption of axonal targets (St. John and Key, 2005).

Reinforcement learning was markedly slowed in both WT and $\mathrm{KO}$ mice after maintenance on fatty diet, whereas the capacity for, but not the rate of, reversal learning was most greatly perturbed through diet in WT mice. It has been suggested that failure to reversal learn reflects an inability to update affective associations between stimuli and reinforcement value as encoded by orbitofrontal circuitry (Egerton et al., 2005; Schoenbaum and Shaham, 2008; Sokolic et al., 2011). Given that obesity and addiction share cellular and anatomical reward circuits, it is interesting that odor reversal learning was highly impaired in our WT HF (obese) mice and similarly impaired after chronic cocaine exposure as reported previously (Stalnaker et al., 2009; Lucantonio et al., 2012). Cognitive impairments after obesity or addiction, or even old age (Schoenbaum et al., 2002a), in terms of behavioral inflexiblity, may therefore be attributed to the same brain systems that demonstrate the inability to change the response to a stimulus, or reversal learn. Kanoski et al. (2007) reported that maintenance of rats on a high-fat diet with dextrose as the primary carbohydrate source impaired auditory reversal learning because of a reduction of BDNF in the prefrontal cortex and the ventral hippocampus. If BDNF were concomitantly reduced in the $\mathrm{OB}$ as observed in the cortex and hippocampus (Kanoski et al., 2007; 
Park et al., 2010), decreased BDNF-induced phosphorylation of Kv1.3 channel (Tucker and Fadool, 2002) would be predicted to decrease olfactory sensitivity. Kv1.3 $3^{-1-}$ mice took significantly longer to learn the new $\mathrm{S}^{+}$identity after the initial reversal switch but curiously were able to reversal learn more expediently upon subsequent reversal learning challenges, behaviors not observed in WT mice. This may indicate that the Kv1.3 channel is involved in plasticity needed to initially modify a learned behavior that is required for relearning processes.

Our findings that the behavioral modulation is not reversible following a "dieting" interval is a serious potential consequence of high-fat consumption during what may be a developmental critical period (Benton, 2010). Although we challenged early postnatal mice with a diet high in fat, it would be interesting to explore other potential, developmental windows. Given that Singh-Manoux et al. (2012) have reported a link between impaired cognition and obesity in humans during midlife, exposure of adult mice to high-fat diets (either short- or long-term) might further accentuate our reported olfactory anatomical losses. Indeed, endurance exercise training of mice after the consumption of a high-fat diet was not able to prevent accumulation of lipids in the hypothalamus (Borg et al., 2012), also pointing to a long-term consequence of fat in the diet. The long-term and reversibility of modulation of the nervous system attributed to DIO requires further exploration, particularly with respect to our chemosensory systems that coordinate with energy intake. It will be important to determine whether anatomical loss of OSNs and OR protein expression is reversible after improved nutrition or exercise, whether these losses perpetuate a chronically altered functionality.

\section{References}

Aimé P, Duchamp-Viret P, Chaput MA, Savigner A, Mahfouz M, Julliard AK (2007) Fasting increases and satiation decreases olfactory detection for a neutral odor in rats. Behav Brain Res 179:258 -264. CrossRef Medline

Andrikopoulos S, Blair AR, Deluca N, Fam BC, Proietto J (2008) Evaluating the glucose tolerance test in mice. Am J Physiol Endocrinol Metab 295: E1323-E1332. CrossRef Medline

Balthasar N (2006) Genetic dissection of neuronal pathways controlling energy homeostasis. Obesity 14:222S-227S. CrossRef Medline

Balthasar N, Dalgaard LT, Lee CE, Yu J, Funahashi H, Williams T, Ferreira M, Tang V, McGovern RA, Kenny CD, Christiansen LM, Edelstein E, Choi B, Boss O, Aschkenasi C, Zhang CY, Mountjoy K, Kishi T, Elmquist JK, Lowell BB (2005) Divergence of melanocortin pathways in the control of food intake and energy expenditure. Cell 123:493-505. CrossRef Medline

Barnea G, O'Donnell S, Mancia F, Sun X, Nemes A, Mendelsohn M, Axel R (2004) Odorant receptors on axon termini in the brain. Science 304: 1468. CrossRef Medline

Benton D (2010) Neurodevelopment and neurodegeneration: are there critical stages for nutritional intervention? Nutr Rev 68:S6-S10. CrossRef Medline

Berthoud HR, Sutton GM, Townsend RL, Patterson LM, Zheng H (2006) Brainstem mechanisms integrating gut-derived satiety signals and descending forebrain information in the control of meal size. Physiol Behav 89:517-524. CrossRef Medline

Biju KC, Marks DR, Mast TG, Fadool DA (2008) Deletion of voltage-gated channel affects glomerular refinement and odorant receptor expression in the mouse olfactory system. J Comp Neurol 506:161-179. CrossRef Medline

Borg ML, Omran SF, Weir J, Meikle PJ, Watt MJ (2012) Consumption of a high-fat diet, but not regular endurance exercise training, regulates hypothalamic lipid accumulation in mice. J Physiol 590:4377-4389. CrossRef Medline

Butler AA, Cone RD (2002) The melanocortin receptors: lessons from knockout models. Neuropeptides 36:77-84. CrossRef Medline

Cao L, Rickenbacher GT, Rodriguez S, Moulia TW, Albers MW (2012) The precision of axon targeting of mouse olfactory sensory neurons requires the BACE1 protease. Sci Rep 2:231. CrossRef Medline
Cavallin MA, Powell K, Biju KC, Fadool DA (2010) State-dependent sculpting of olfactory sensory neurons is attributed to sensory enrichment, odor deprivation, and aging. Neurosci Lett 483:90-95. CrossRef Medline

Cheng K, Bai L, Belluscio L (2011) Fas-associated factor 1 as a regulator of olfactory axon guidance. J Neurosci 31:11905-11913. CrossRef Medline

Collins S, Martin TL, Surwit RS, Robidoux J (2004) Genetic vulnerability to diet-induced obesity in the C57BL/6 J mouse: physiological and molecular characteristics. Physiol Behav 81:243-248. CrossRef Medline

Cook KK, Fadool DA (2002) Two adaptor proteins differentially modulate the phosphorylation and biophysics of Kv1.3 ion channel by SRC kinase. J Biol Chem 277:13268-13280. CrossRef Medline

De Souza CT, Araujo EP, Bordin S, Ashimine R, Zollner RL, Boschero AC, Saad MJ, Velloso LA (2005) Consumption of a fat-rich diet activates a proinflammatory response and induces insulin resistance in the hypothalamus. Endocrinology 146:4192-4199. CrossRef Medline

Doucette W, Gire DH, Whitesell J, Carmean V, Lucero MT, Restrepo D (2011) Associative cortex features in the first olfactory brain relay station. Neuron 69:1176-1187. CrossRef Medline

Egerton A, Brett RR, Pratt JA (2005) Acute 89 -tetrahydrocannabinolinduced deficits in reversal learning: neuroal correlates of affective inflexibility. Neuropsychopharmacology 30:1895-1905. CrossRef Medline

Fadool DA, Tucker K, Phillips JJ, Simmen JA (2000) Brain insulin receptor causes activity-dependent current suppression in the olfactory bulb through multiple phosphorylation of Kv1.3. J Neurophysiol 83:23322348. Medline

Fadool DA, Tucker K, Perkins R, Fasciani G, Thompson RN, Parsons AD, Overton JM, Koni PA, Flavell RA, Kaczmarek LK (2004) Kv1.3 channel gene-targeted deletion produces "Super-Smeller Mice" with altered glomeruli, interacting scaffolding proteins, and biophysics. Neuron 41: 389-404. CrossRef Medline

Fadool DA, Tucker K, Pedarzani P (2011) Mitral cells of the olfactory bulb perform metabolic sensing and are disrupted by obesity at the level of the Kv1.3 ion channel. PLoS One 6:e24921. CrossRef Medline

Feinstein P, Mombaerts P (2004) A contextual model for axonal sorting into glomeruli in the mouse olfactory system. Cell 117:817-831. CrossRef Medline

Feinstein P, Bozza T, Rodriguez I, Vassalli A, Mombaerts P (2004) Axon guidance of mouse olfactory sensory neurons by odorant receptors and the beta2 adrenergic receptor. Cell 117:833-846. CrossRef Medline

Fleischmann A, Shykind BM, Sosulski DL, Franks KM, Glinka ME, Mei DF, Sun Y, Kirkland J, Mendelsohn M, Albers MW, Axel R (2008) Mice with a "Monoclonal Nose": perturbations in an olfactory map impair odor discrimination. Neuron 60:1068-1081. CrossRef Medline

Gavrieli Y, Sherman Y, Ben-Sasson SA (1992) Identification of programmed cell death in situ via specific labeling of nuclear DNA fragmentation. J Cell Biol 119:493-501. CrossRef Medline

Gerdes J, Lemke H, Baisch H, Wacker HH, Schwab U, Stein H (1984) Cell cycle analysis of a cell proliferation-associated human nuclear antigen defined by the monoclonal antibody Ki-67. J Immunol 133:1710-1715. Medline

Gregor MF, Hotamisligil GS (2011) Inflammatory mechanisms in obesity. Annu Rev Immunol 29:415-445. CrossRef Medline

Hedley AA, Ogden CL, Johnson CL, Carroll MD, Curtin LR, Flegal KM (2004) Prevalence of overweight and obesity among US children, adolescents, and adults, 1999-2002. JAMA 291:2847-2850. CrossRef Medline

Huszar D, Lynch CA, Fairchild-Huntress V, Dunmore JH, Fang Q, Berkemeier LR, Gu W, Kesterson RA, Boston BA, Cone RD, Smith FJ, Campfield LA, Burn P, Lee F (1997) Targeted disruption of the melanocortin-4 receptor results in obesity in mice. Cell 88:131-141. CrossRef Medline

Jones DT, Reed RR (1989) Golf: an olfactory neuron specific-G protein involved in odorant signal transduction. Science 244:790-795. CrossRef Medline

Kanoski SE, Meisel RL, Mullins AJ, Davidson TL (2007) The effects of energy-rich diets on discrimination reversal learning and on BDNF in the hippocampus and prefrontal cortex of the rat. Behav Brain Res 182:5766. CrossRef Medline

Kleinridders A, Schenten D, Könner AC, Belgardt BF, Mauer J, Okamura T, Wunderlich FT, Medzhitov R, Brüning JC (2009) MyD88 signaling in the CNS is required for development of fatty acid-induced leptin resistance and diet-induced obesity. Cell Metab 10:249-259. CrossRef Medline

Lacroix MC, Badonnel K, Meunier N, Tan F, Schlegel-Le Poupon C, Durieux 
D, Monnerie R, Baly C, Congar P, Salesse R, Caillol M (2008) Expression of insulin system in the olfactory epithelium: first approaches to its role and regulation. J Neuroendocrinol 20:1176-1190. CrossRef Medline

Lewcock JW, Reed RR (2004) A feedback mechanism regulates monoallelic odorant receptor expression. Proc Natl Acad Sci U S A 101:1069-1074. CrossRef Medline

Lucantonio F, Stalnaker TA, Shaham Y, Niv Y, Schoenbaum G (2012) The impact of orbitofrontal dysfunction on cocaine addiction. Nat Neurosci 15:358-366. CrossRef Medline

Mania-Farnell B, Farbman AI (1990) Immunohistochemical localization of guanine nucleotide-binding proteins in rat olfactory epithelium during development. Brain Res Dev Brain Res 51:103-112. CrossRef Medline

Marks DR, Tucker K, Cavallin MA, Mast TG, Fadool DA (2009) Awake intranasal insulin delivery modifies protein complexes and alters memory, anxiety, and olfactory behaviors. J Neurosci 29:6734-6751. CrossRef Medline

Martyn JA, Kaneki M, Yasuhara S (2008) Obesity-induced insulin resistance and hyperglycemia: etiologic factors and molecular mechanisms. Anesthesiology 109:137-148. CrossRef Medline

McNay DE, Briançon N, Kokoeva MV, Maratos-Flier E, Flier JS (2012) Remodeling of the arcuate nucleus energy-balance circuit is inhibited in obese mice. J Clin Invest 122:142-152. CrossRef Medline

Menco BP, Tekula FD, Farbman AI, Danho W (1994) Developmental expression of G-proteins and adenylyl cyclase in peripheral olfactory systems: light microscopic and freeze-substitution electron microscopic immunocytochemistry. J Neurocytol 23:708-727. CrossRef Medline

Mombaerts P, Wang F, Dulac C, Chao SK, Nemes A, Mendelsohn M, Edmondson J, Axel R (1996) Visualizing an olfactory sensory map. Cell 87:675-686. CrossRef Medline

Moraes JC, Coope A, Morari J, Cintra DE, Roman EA, Pauli JR, Romanatto T, Carvalheira JB, Oliveira AL, Saad MJ, Velloso LA (2009) High-fat diet induces apoptosis of hypothalamic neurons. PLoS One 4:e5045. CrossRef Medline

Ohsawa S, Hamada S, Yoshida H, Miura M (2008) Caspase-mediated changes in histone $\mathrm{H} 1$ in early apoptosis: prolonged caspase activation in developing olfactory sensory neurons. Cell Death Diff 15:1429-1439. CrossRef Medline

Park HR, Park M, Choi J, Park KY, Chung HY, Lee J (2010) A high-fat diet impairs neurogenesis: involvement of lipid peroxidation and brainderived neurotrophic factor. Neurosci Lett 482:235-239. CrossRef Medline

Palouzier-Paulignan B, Lacroix MC, Aimé P, Baly C, Caillol M, Congar P, Julliard AK, Tucker K, Fadool DA (2012) Olfaction under metabolic influences. Chem Senses 37:769-797. CrossRef Medline

Perez JA, Clinton SM, Turner CA, Watson SJ, Akil H (2009) A new role for FGF2 as an endogenous inhibitor of anxiety. J Neurosci 29:6379-6387. CrossRef Medline

Pierce AA, Xu AW (2010) De novo neurogenesis in adult hypothalamus as a compensatory mechanism to regulate energy balance. J Neurosci 30:723730. CrossRef Medline

Potter SM, Zheng C, Koos DS, Feinstein P, Fraser SE, Mombaerts P (2001) Structure and emergence of specific olfactory glomeruli in the mouse. J Neurosci 21:9713-9723. Medline

Prud'homme MJ, Lacroix MC, Badonnel K, Gougis S, Baly C, Salesse R, Caillol M (2009) Nutritional status modulates behavioural and olfactory bulb Fos responses to isoamyl acetate or food odour in rats: roles of orexins and leptin. Neuroscience 164:1287-1298. CrossRef Medline

Ressler KJ, Sullivan SL, Buck LB (1993) A zonal organization of odorant receptor gene expression in the olfactory epithelium. Cell 73:597-609. Medline

Rochefort C, Gheusi G, Vincent JD, Lledo PM (2002) Enriched odor exposure increases the number of newborn neurons in the adult olfactory bulb and improves odor memory. J Neurosci 22:2679-2689. Medline

Schoenbaum G, Shaham Y (2008) The role of orbitofrontal cortex in drug addiction: a review of preclinical studies. Biol Psychiatry 63:256-262. CrossRef Medline

Schoenbaum G, Nugent S, Saddoris MP, Gallagher M (2002a) Teaching old rats new tricks: age-related impairments in olfactory reversal learning. Neurobiol Aging 23:555-564. CrossRef Medline

Schoenbaum G, Nugent SL, Saddoris MP, Setlow B (2002b) Orbitofrontal lesions in rats impair reversal but not acquisition of go, no-go odor discriminations. Neuroreport 13:885-890. CrossRef Medline

Serizawa S, Miyamichi K, Nakatani H, Suzuki M, Saito M, Yoshihara Y, Sakano H (2003) Negative feedback regulation ensures the one receptor-one olfactory neuron rule in mouse. Science 302:2088-2094. CrossRef Medline

Singh-Manoux A, Czernichow S, Elbaz A, Dugravot A, Sabia S, HaggerJohnson G, Kaffashian S, Zins M, Brunner EJ, Nabi H, Kivimaki M (2012) Obesity phenotypes in midlife and cognition in early old age: the Whitehall II cohort study. Neurol 79:755-762. CrossRef Medline

Slotnick B, Restrepo D (2005) Olfactometry with mice. Curr Protoc Neurosci 8.

Sokolic L, Long LE, Hunt GE, Arnold JC, McGregor IS (2011) Disruptive effects of the prototypical cannabinoid ${ }_{\Delta} 9$-tetrahydrocannabinol and the fatty acid amide inhibitor URB-597 on go/no-go auditory discrimination performance and olfactory reversal learning in rats. Behav Pharmacol 22:191-202. CrossRef Medline

Stalnaker TA, Takahashi Y, Roesch MR, Schoenbaum G (2009) Neural substrates of cognitive inflexibility after chronic cocaine exposure. Neuropharmacology 56:63-72. CrossRef Medline

St. John JA, Key B (2005) Olfactory marker protein modulates primary olfactory axon overshooting in the olfactory bulb. J Comp Neurol 488:6169. CrossRef Medline

Sultan B, May LA, Lane AP (2011) The role of TNF- $\alpha$ in inflammatory olfactory loss. Laryngoscope 121:2481-2486. CrossRef Medline

Tucker K, Fadool DA (2002) Neurotrophin modulation of voltage-gated potassium channels in rat through $\operatorname{TrkB}$ receptors is time and sensory experience dependent. J Physiol 542:413-429. CrossRef Medline

Tucker K, Overton JM, Fadool DA (2008) Kv1.3 gene-targeted deletion alters longevity and reduces adiposity by increasing locomotion and metabolism in melanocortin-4 receptor-null mice. Int J Obes 32:1222-1232. CrossRef Medline

Tucker KR, Godbey SJ, Thiebaud N, Fadool DA (2012a) Olfactory ability and object memory in three mouse models of varying body weight, metabolic hormones, and adiposity. Physiol Behav 107:424-432. CrossRef Medline

Tucker K, Overton JM, Fadool DA (2012b) Diet-induced obesity resistance of Kv1.3 $3^{-1-}$ mice is olfactory bulb dependent. J Neuroendocrinol 24: 1087-1095. CrossRef Medline

Tucker K, Cho S, Thiebaud N, Henderson MX, Fadool DA (2013) Glucose sensitivity of mouse olfactory bulb neurons is conveyed by a voltage-gated potassium channel. J Physiol 591:2541-2561. Medline

Watt WC, Sakano H, Lee ZY, Reusch JE, Trinh K, Storm DR (2004) Odorant stimulation enhances survival of olfactory sensory neurons via MAPK and CREB. Neuron 41:955-967. CrossRef Medline

West DB, Boozer CN, Moody DL, Atkinson RL (1992) Dietary obesity in nine inbred mouse strains. Am J Physiol Regul Integr Comp Physiol 262: R1025-R1032. Medline

Williams TD, Chambers JB, Roberts LM, Henderson RP, Overton JM (2003) Diet-induced obesity and cardiovascular regulation in C57BL/6J mice. Clin Exp Pharmacol Physiol 30:769-778. CrossRef Medline

Xu J, Koni PA, Wang P, Li G, Kaczmarek L, Wu Y, Li Y, Flavell RA, Desir GV (2003) The voltage-gated potassium channel Kv1.3 regulates energy homeostasis and body weight. Hum Mol Genet 12:551-559. CrossRef Medline

Xu J, Wang P, Li Y, Li G, Kaczmarek LK, Wu Y, Koni PA, Flavell RA, Desir GV (2004) The voltage-gated potassium channel Kv1.3 regulates peripheral insulin sensitivity. Proc Natl Acad Sci U S A 101:3112-3117. CrossRef Medline

Yeomans MR (2006) Olfactory influences on appetite and satiety in humans. Physiol Behav 87:800-804. CrossRef Medline

Yi CX, Al-Massadi O, Donelan E, Lehti M, Weber J, Ress C, Trivedi C, Müller TD, Woods SC, Hofmann SM (2012) Exercise protects against high-fat diet-induced hypothalamic inflammation. Physiol Behav 106:485-490. CrossRef Medline

Zhang X, Zhang G, Zhang H, Karin M, Bai H, Cai D (2008) Hypothalamic IKKbeta/NF-kappaB and ER stress link overnutrition to energy imbalance and obesity. Cell 135:61-73. CrossRef Medline

Zheng C, Feinstein P, Bozza T, Rodriguez I, Mombaerts P (2000) Peripheral olfactory projections are differentially affected in mice deficient in a cyclic nucleotide-gated channel subunit. Neuron 26:81-91. CrossRef Medline 